\title{
RESPOSTA DOS TECIDOS PERIRRADICULARES APÓS SELAMENTO DE PERFURAÇÕES DE FURCA COM BIODENTINE OU MTA
}

Tese apresentada à Faculdade de Odontologia de Ribeirão Preto da Universidade de São Paulo para obtenção do título de doutora em Ciências. Programa: Odontopediatria Área de concentração: Odontopediatria Orientadora: Profa. Dra. Alexandra Mussolino de Queiroz Co-Orientadora: Profa. Dra. Léa Assed Bezerra da Silva 


\section{AUTORIZAÇÃO PARA REPRODUÇÃO}

Autorizo a reprodução e divulgação total ou parcial deste trabalho, por qualquer meio convencional ou eletrônico para fins de estudo e pesquisa, desde que citada a fonte.

KARINA ALESSANDRA MICHELÃO GRECCA PIERONI

\section{FICHA CATALOGRÁFICA}

Pieroni, Karina Alessandra Michelão Grecca

Resposta dos Tecidos Perirradiculares após Selamento de Perfurações de Furca com Biodentine ou MTA. Ribeirão Preto, 2017.

101p.: il.; $30 \mathrm{~cm}$

Tese apresentada à Faculdade de Odontologia de Ribeirão Preto da Universidade de São Paulo para obtenção do título de doutora em Ciências. Programa: Odontopediatria

Orientadora: Queiroz, Alexandra Mussolino de

1. Biodentine Perfuração de furca. 2. Análise histopatologica. 3. MTA. RUNX2. 
Pieroni, KAMG. Resposta dos Tecidos Perirradiculares após Selamento de Perfurações de Furca com Biodentine ou MTA.

Tese apresentada à Faculdade de Odontologia de Ribeirão Preto da Universidade de São Paulo para obtenção do título de doutora em Ciências. Programa: Odontopediatria. Área de concentração: Odontopediatria.

Data da defesa:

\section{BANCA EXAMINADORA}

$\operatorname{Prof}(a) . \operatorname{Dr}(a)$

Instituição:

Julgamento: Assinatura:

$\operatorname{Prof}(a) . \operatorname{Dr}(a)$.

Instituição:

Julgamento: Assinatura:

$\operatorname{Prof}(a) . \operatorname{Dr}(a)$.

Instituição:

Julgamento: Assinatura:

Prof(a). Dr(a).

Instituição:

Julgamento: Assinatura:

$\operatorname{Prof}(a) . \operatorname{Dr}(a)$.

Instituição:

Julgamento: Assinatura: 



\section{DADOS CURRICULARES}

\section{KARINA ALESSANDRA MICHELÃO GRECCA PIERONI}

Nascimento- 14 de janeiro de 1973 - Bauru/SP

Filiação- Marco Antonio Grecca

Zilda Michelão Grecca

1992-1996- Curso de Graduação.

Universidade de Sagrado Coração - USC/Bauru.

1996-1998- Especialização em Dentística Restauradora pelo Hospital de Pesquisa e Reabilitação de Lesões Lábio Palatais - HRAC/ USP - Bauru.

1998-1999- Curso de Aperfeiçoamento em Prótese pela Universidade do Sagrado Coração- USC/Bauru.

1999-2000 - Curso de Aperfeiçoamento em Endodontia pela Fundação para o Estudo e Tratamento das Deformidades Craniofaciais - FUNCRAF - Bauru.

2000-2002- Especialização na área de Prótese Dentária pelo Hospital de Pesquisa e Reabilitação de Lesões Lábio Palatais - HRAC/ USP - Bauru.

2009-2013- Curso de Aperfeiçoamento no Atendimento de pacientes especiais no CAOPE/FORP - USP.

2011-2013- Curso de Pós-Graduação em Odontopediatria, nível de Mestrado Faculdade de Odontologia de Ribeirão Preto da Universidade de São Paulo - FORP/USP - Dissertação "Liberação de compostos orgânicos das resinas Kalore ${ }^{\mathrm{TM}}$ e Filtek ${ }^{\mathrm{TM}}$ Silorane em função da fonte polimerizadora, da solução de imersão e do pH".

2013-2017- Curso de Pós-Graduação em Odontopediatria, nível de Doutorado Faculdade de Odontologia de Ribeirão Preto da Universidade de São Paulo - FORP/USP - Tese "Resposta dos tecidos perirradiculares após selamento de perfurações de furca com Biodentine ou MTA".

2014- Cirurgiã-dentista Odontopediatra contratada do Departamento de Odontologia e Estomatologia do Hospital das Clínicas da Faculdade de Medicina de Ribeirão-Preto/USP. 

À Deus e Nossa Senhora,

Por tornar meus sonhos realidade...

Por guiar as decisões da minha vida, onde sempre procuro fazer e dar o melhor de $\operatorname{mim} \ldots$

Aos meus filhos Diego e Manuela, minhas joias preciosas,

Aos filhos que são minha luz, meu caminho, meu norte! Agradeço todos os dias à felicidade de chamá-los de meus filhos!

Que os momentos da minha ausência seja para vocês um exemplo positivo de dedicação, de ampliação de conhecimentos e estímulo para o estudo constante. Eu amo vocês!!!!

\section{Obrigado meus queridos!}

Ao meu marido Fabiano

Sempre presente em minha vida, ter você ao meu lado, foi muito importante para alcançar meus objetivos. Te amo muito! 

Aos meus queridos pais, Marco Antonio e Zilda,

Por serem exatamente como são; feliz de mim ter o privilégio de ser sua filha! Obrigada pelos braços sempre abertos, pelas palavras de incentivo e confiança, pelo amor explicito nos seus olhos!

Amo vocês!

\section{Ao meu irmão Marco Antonio,}

Ah, meu irmão... você é simplesmente maravilhoso! Um amigo pra sempre! Os momentos que compartilhamos são de um valor inestimável para mim! Te admiro demais!

Obrigada pelo incentivo constante, pelos conselhos... obrigada !!!!!!

\section{Ao meu irmão Luiz Gustavo (in memorian)}

Você, que cedo partiu, deixando um vazio.... e lindas lembranças...

Eternamente presente em minha vida... Um amigo, uma vida com tantas alegrias... Certamente estaria compartilhando comigo da felicidade de mais uma etapa cumprida em minha vida!

Para sempre meu anjo de luz! Te amo! 

Ã minha orientadora profa. Dra. Alexandra Mussolino de Queiroz,

Pessoa maravilhosa, meiga, justa, de tamanha sabedoria! Agradeço a oportunidade que tive durante este período de poder contar com seus ensinamentos e seguir seus exemplos profissionais! Obrigada por tudo!

À profa. Dra. Léa Assed Bezerra da Silva,

Admirável... Agradeço a oportunidade de poder ter feito parte de um departamento tão dedicado aos cuidados dos pequeninos em todos seus aspectos!

Meu sincero respeito e admiração!

Aos cirurgiões dentistas contratados da odontopediatria da Faculdade de Odontologia da Universidade de São Paulo, Ribeirão - Preto/SP, Francisco Wanderley Garcia de Paula e Silva e Marilia Pacifico Lucisano,

Meus sinceros agradecimentos, gratidão e reconhecimento pela disponibilidade e ajuda fundamental para a realização deste trabalho.

Muitîssimo obrigada!

Aos professores do Odontopediatria da Faculdade de Odontologia de Ribeirão Preto da Universidade de São Paulo; profa. Dra Raquel Assed Bezerra Segato; profa.Dra. Kranya Victória Díaz-Serrano; profa. Dra. Andiara de Rossi Daldegan; profa. Dra. Maria Cristina Borsatto; profa. Dra. Aldevina de Campos Fraga; profa. Dra. Maria Conceição Pereira Saraiva; prof. Dr. Paulo Nelson Filho e prof. Dr. Fabrício Kitazono de Carvalho,

Meus sinceros agradecimentos a cada um de vocês, que de alguma forma em algum momento contribuíram para meu crescimento intelectual e formação profissional!

Todo meu carinho e respeito! 
Aos funcionários do Departamento de Odontopediatria, Filomena Leli Placciti; Matheus Morelli Zanela; Micheli Cristina Leite Rovanholo,

Meus mais sinceros agradecimentos pelo carinho, pela atenção, pela disponibilidade, pelas palavras de estímulo, pela amizade!

De coração..... muitíssimo obrigado!!!!!

Aos funcionários do laboratório de Histologia do Departamento de Odontopediatria, Fătima Aparecida Jacinto; Marco Antonio dos Santos e Nilza Letícia Magalhães,

Pessoas de extrema gentileza.... sempre! Foram de inestimável importância para a realização deste trabalho!

Todo meu carinho a cada um de vocês!

Aos funcionărios da seção de Pós-graduação da Faculdade de Odontologia de Ribeirão Preto da Universidade de São Paulo, Isabel Cristina Galmo Sola; Regiane Cristina Moi Sacillioto e Leandro Marin Silva,

Pela dedicação incondicional e pelo carinho que sempre demonstraram, meus sinceros agradecimentos!

À funcionāria da Secretaria do curso de Ortodontia, Rosemary Alves de Sá,

Meus sinceros agradecimentos pela delicadeza e boa vontade que sempre me atendeu! Pessoa fundamental para a conclusão deste trabalho!

Todo meu reconhecimento e gratidão!

A todos os profissionais do Departamento de Odontologia e Estomatologia do Hospital das Clínicas de Ribeirão-Preto/USP-São Paulo, Dr. Leandro Dorigan de Macedo; Dra. Lara Maria A. Ramos Innocentini; Tatiane Cristina Ferrari; Vanessa Shcaira Rocha;

Pelo incentivo constante durante toda essa importante etapa de minha vida!

Obrigada pela amizade sincera de cada um de vocês!

Agradeço e sou imensamente feliz e realizada por fazer parte desta equipe! 


\section{RESUMO}

\section{Pieroni, KAMG. Resposta dos tecidos perirradiculares após selamento de perfurações}

de furca com Biodentine ou MTA. 101p. [Tese de Doutorado]. Ribeirão Preto: Faculdade de Odontologia de Ribeirão Preto da Universidade de São Paulo; 2017.

O objetivo deste estudo foi avaliar a resposta dos tecidos perirradiculares após perfuração de furca intencional e selamento com Biodentine (BD), agregado trióxido mineral (MTA) ou guta percha. Foram utilizados pré-molares de 3 cães, num total de 30 dentes, distribuídos em 3 grupos: experimental BD $(n=14)$, controle negativo (MTA) $(n=10)$ e controle positivo (guta percha) $(n=6)$, por um período de 120 dias. Radiograficamente foi analisada a área correspondente à perfuração de furca. $\mathrm{Na}$ análise histopatológica qualitativa foi avaliada a presença, ou não de tecido mineralizado no local da perfuração de furca e adjacências. Na análise histopatológica semi-quantitativa foram atribuídos escores para os parâmetros: presença ou ausência de tecido mineralizado, intensidade do processo inflamatório e reabsorção dos tecidos mineralizados. $\mathrm{Na}$ análise histopatológica quantitativa foi medida a espessura de tecido mineralizado na área de perfuração de furca. Foram realizados ensaios de imuno-histoquímica para os marcadores de mineralização: RANKL e osteoprotegerina (OPG). Ensaio de imunofluorescência indireta avaliou a expressão Runx-2 para a síntese de proteínas de mineralização. Os dados foram avaliados pelos testes qui-quadrado, teste exato de Fisher e teste de Mann Whitney, utilizando o programa estatístico Graph Pad Prism 6.0. Os grupos foram comparados entre sí pelo Teste de Kruskal Wallis com pós-teste de Dunn. O nível de significância adotado para todas as análises foi de $5 \%$. Na análise radiográfica a $(\mathrm{BD})$ apresentou melhor desempenho em relação ao $\mathrm{MTA}$, em todos os aspectos analisados. Histologicamente, tanto o MTA quanto a BD induziram a formação de tecido mineralizado, quando comparado à guta percha, que não induziu a formação de tecido mineralizado $(p<.001)$. O selamento completo das perfurações de furca foi mais frequente com o MTA, que induziu a deposição de tecido mineralizado com área e espessura maiores. Tanto as amostras seladas com BD, quanto com MTA, não apresentaram reabsorção óssea em área de furca, apresentaram poucas células inflamatórias e maior intensidade do imunomarcador RUNX2 quando comparadas com a guta percha. A OPG esteve presente em amostras seladas com BD e com MTA. Embora o MTA tenha apresentado maior frequência de selamento completo e maior área e espessura de tecido mineralizado recém-formado, a BD também apresentou bons resultados histopatológicos e pode ser considerada como um adequado material de selamento de perfuração de furca.

Palavras-chave: Biodentine Perfuração de furca. Análise histopatologica. MTA. RUNX2. 



\section{ABSTRACT}

Pieroni, AMG. Response of periradicular tissue after sealing of furcation perforation with Biodentine or MTA. 101p. [Tese de Doutorado]. Ribeirão Preto: University of São Paulo, School of Dentistry of Ribeirão Preto; 2017.

The objective of this study was to evaluate the periradicular tissue response after intentional furcation and sealing with Biodentine (BD), mineral trioxide aggregate (MTA) or gutta percha. Pre-molars of 3 dogs were used, in a total of 30 teeth, distributed in 3 groups: experimental BD $(n=14)$, negative control (MTA) $(n=10)$ and positive control (gutta percha), for a period of 120 days. The area corresponding to furcation was analyzed radiographically. In the qualitative histopathological analysis, the presence or not of mineralized tissue at the furcation site and adjacent areas was evaluated. In the semi-quantitative histopathological analysis, scores were assigned to the parameters: presence or absence of mineralized tissue, intensity of the inflammatory process and reabsorption of mineralized tissues. In the quantitative histopathological analysis the thickness of mineralized tissue in the furcation area was measured. Immunohistochemical assays were performed for the mineralization markers: RANKL and osteoprotegerin (OPG). Indirect immunofluorescence assay evaluated RUNX-2 expression for the synthesis of mineralization proteins. Data were evaluated by chisquare test, Fisher exact test and Mann Whitney test using the Graph Pad Prism 6.0 statistical software. The groups were compared by the Kruskal Wallis test with Dunn's posttest. The level of significance adopted for all analyzes was $5 \%$. In the radiographic analysis the (BD) presented better performance in relation to the MTA, in all aspects analyzed. Histologically, both MTA and BD induced the formation of mineralized tissue when compared to gutta percha, which did not induce the formation of mineralized tissue $(p<.001)$. The complete sealing of furcation holes was more frequent with the MTA, which induced the deposition of mineralized tissue with a larger and thickness area. Both the BD and MTA sealed samples did not show bone resorption in the furcation area, showed few inflammatory cells and a greater intensity of the RUNX2 immunomarker when compared to the gutta percha. OPG was present in samples sealed with BD and with MTA. Although the MTA presented higher frequency of complete sealing and greater area and thickness of newly formed mineralized tissue, BD also presented good histopathological results and can be considered as a suitable furcation perforation sealing material.

Key-words: Biodentine Furcation perforation. Histopthatological analysis. MTA. RUNX2. 



\section{SUMÁRIO}

1. INTRODUÇÃO

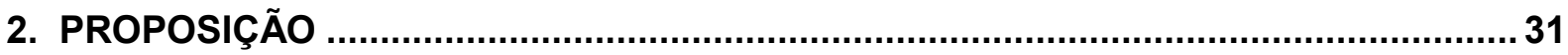

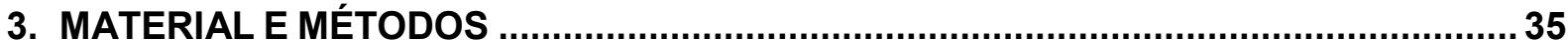

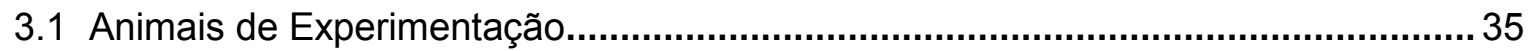

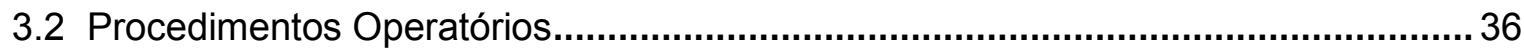

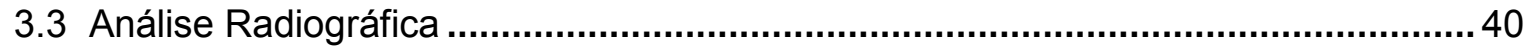

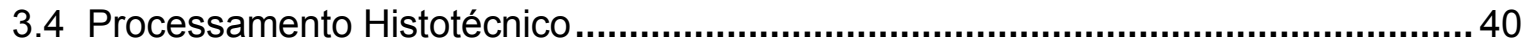

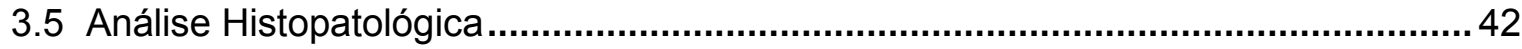

3.6 Análise Imuno-Histoquímica - Análise da marcação para RANKL e

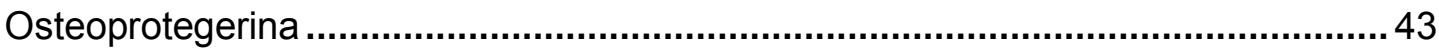

3.7 Análise de Imunofluorescência Indireta - Análise das células positivamente marcadas para o fator de transcrição RUNX2 ................................................... 44

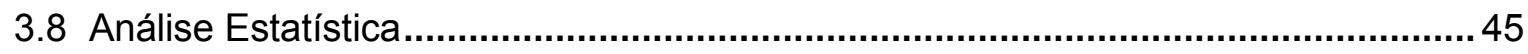

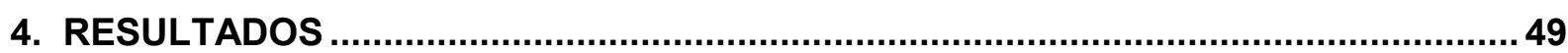

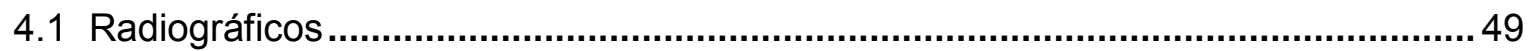

4.2 Imuno-histoquímica - Análise da marcação para RANKL/OPG ............................... 59

4.3 Imunofluorescência indireta - Análise das células positivamente marcadas para o fator de transcrição RUNX-2 ....................................................................... 65

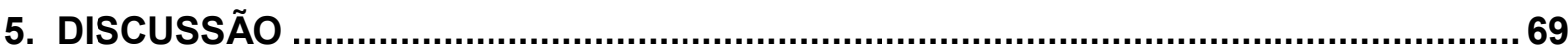

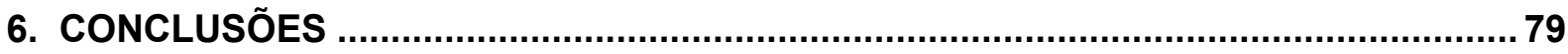

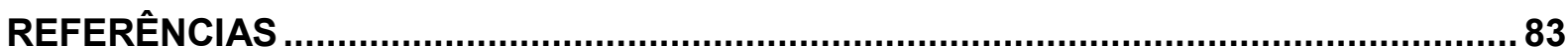

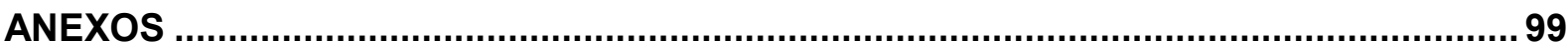



1. INTRODUÇÃO 



\section{INTRODUÇÃO}

As perfurações de furca são comunicações iatrogênicas ou patológicas (decorrentes de lesões de cárie ou reabsorções dentais) entre o canal radicular e o assoalho da câmara pulpar e os tecidos perirradiculares (Sinai, 1977; Jew et al., 1982; Hamad et al., 2006; Tsesis; Fuss, 2006; Zairi et al., 2012; Aggarwall et al., 2013; Sanghavi et al., 2013; Nishtha et al., 2014; Katge; Shivasharan; Patil, 2016).

As perfurações no assoalho da câmara pulpar dos dentes multirradiculares, são a segunda causa de insucesso após tratamento endodôntico de dentes multirradiculares (Seltzer, 1967) e apresentam pior prognóstico, quando comparadas às perfurações nos terços médio e apical da raiz. Isso decorre da estreita proximidade com o ambiente bucal por meio do sulco gengival e do epitélio juncional, que propícia a contaminação e apresenta um potencial elevado para causar uma bolsa periodontal, provocando danos ao ligamento periodontal com uma subsequente reação inflamatória ocasionando a perda de inserção periodontal na área afetada (Seltzer et al., 1970; Sinai, 1977; Meister et al., 1979; Alhadainy; Himel, 1993; Ferris; Baumgartner, 2004; Bargholz, 2005; Hamad et al., 2006; Hashem; Hassanien, 2008; Silva MJ et al., 2009; Vanni et al., 2010; Azim; Lloyd; Huang, 2014; Nishtha et al., 2014; Katge; Shivasharan; Patil, 2016); podendo também evoluir com reabsorção óssea, dentinária e/ou cementária (Seltzer et al., 1970; Sinai, 1977; Meister et al., 1979; Alhadainy; Himel, 1993; Nishtha et al., 2014; Katge; Shivasharan; Patil, 2016).

Os tecidos perirradiculares adjacentes às perfurações contêm uma grande variedade de células imunocompetentes, que desempenham um papel importante na patogênese da inflamação e nos mecanismos de reparação tecidual (Ferris; Baumgartner, 2004; Tsesis; Fuss, 2006; Hashem; Hassanien, 2008). A primeira defesa do organismo a um dano tecidual é a resposta inflamatória. A inflamação é um processo biológico complexo que envolve componentes vasculares, celulares e uma diversidade de substâncias solúveis, apresentando como sinais clínicos característicos rubor, calor, edema, dor e prejuízo funcional. A finalidade do processo inflamatório é remover o estímulo lesivo e iniciar a recuperação tecidual local (Mesquita Jr et al., 2008). 
Durante a inflamação vários sistemas bioquímicos, como o sistema do complemento e da coagulação, são ativados auxiliando no estabelecimento, evolução e resolução do processo. Adicionalmente, várias substâncias solúveis de meia vida curta são liberadas, exercendo sua ação e sendo degradadas no sítio inflamatório (Mesquita Jr et al., 2008). Em geral, o sucesso na remoção do estímulo lesivo leva à conclusão do processo e término da resposta aguda, ensejando o processo de reparo tecidual completo. Nesse processo predominam elementos da resposta imune inata, mas podem participar também linfócitos, plasmócitos e anticorpos (Mesquita Jr et al., 2008). Por outro lado, na inflamação crônica, em geral ocasionada por persistência do estímulo tóxico, o processo inflamatório se mantém e sofre alterações qualitativas, caracterizadas por mudança progressiva nos elementos celulares e solúveis que infiltram o tecido. Ocorre maior envolvimento da imunidade adquirida, de células imunocompetentes, macrófagos e fibroblastos, aumentando as probabilidades de que a reconstituição não seja completa. Macrófagos residentes no tecido lesado liberam citocinas inflamatórias como IL-1, TNF- $\alpha$ e quimiocinas (Mesquita Jr et al., 2008).

As células imunes presentes na lesão perirradicular consistem em linfócitos, macrófagos, células plasmáticas, neutrófilos e células NK (natural killer). Dentro dos linfócitos, as células T estão em maior número ou iguais às células B (Torabinejad; Kettering, 1985; Niederman et al., 2001; Liapatas; Nakou; Rontogianni, 2003; Mesquita Jr et al., 2008).

O prognóstico das perfurações de furca, à longo prazo, está diretamente relacionado com o tamanho da lesão, tempo de exposição à contaminação bucal, localização da perfuração, técnica operatória e material utilizado para o selamento da perfuração (Sinai, 1977; Cau et al., 1997; Jew et al., 1982; EIDeeb et al., 1982; Lee et al., 1993; Ford et al., 1995; Bogaerts, 1997; El Tawil et al., 2011; Ma et al., 2011; Aggarwall et al., 2013; Eppala, 2014; Nishtha et al., 2014; Katge; Shivasharan; Patil, 2016).

As perfurações de furca podem ser seladas por meio de técnicas de tratamento intra-coronário ou acesso cirúrgico externo (Alhadainy, 1994; Noetzel et al., 2006; Mente et al., 2010). Entretanto, a intervenção intra-coronária deve ser a técnica de escolha inicial, antes que se decida pelo uso da técnica cirúrgica (Main et al., 2004; Noetzel et al., 2006; Aggarwal et al., 2013). Além disso, a reparação cirúrgica não é possível em locais como a região lingual da mandíbula e as 
trifurcações de molares. No entanto, independente da técnica, é necessário que haja um selamento eficaz entre a estrutura do dente e o periodonto (elDeeb et al., 1982 ; Vanni et al., 2011).

O material ideal para o selamento das perfurações de furca deve apresentar compatibilidade tecidual, ser radiopaco, ser bacteriostático, não ser reabsorvível, apresentar capacidade de indução da osteogênese e cementogênese, favorecer a reparação dos tecidos envolvidos, ser atóxico, não carcinogênico e genotóxico, possuir estabilidade dimensional e ser de fácil manipulação, além de apresentar uma boa capacidade de vedamento (Nakata, et al., 1998; Sluyk et al., 1998; Torabinejad; Chivian, 1999; Watts et al., 2007; Silveira et al., 2008; Aggarwall et al., 2013; Eppala, 2014; Nishtha et al., 2014).

A interação dos materiais utilizados para selamento das perfurações de furca com os tecidos perirradiculares é influenciada por muitos fatores, incluindo a composição química do material, a concentração dos componentes liberados ou seus produtos de degradação, bem como a capacidade do tecido para responder a estes agentes, além da escolha adequada da técnica de tratamento (Ferracane et al., 2010).

Vários materiais tem sido sugerido para o selamento das perfurações de furca incluindo amálgama (Benenati et al., 1986; Lee et al., 1993; Ferris; Baumgartner, 2004; Katge; Shivasharan; Patil, 2016), cimento de óxido de zincoeugenol, guta-percha, hidróxido de cálcio (Sinai, 1977; Ruddle, 2002; Ferris; Baumgartner, 2004; De-Deus et al., 2006; Hashem; Hassanien, 2008; Katge; Shivasharan; Patil, 2016), Cavit (Jew et al., 1982; Sinai et al., 1989), fosfato tricálcico (Schmitz et al., 1999; Ferris; Baumgartner, 2004; Katge; Shivasharan; Patil, 2016), hidroxiapatita, cimento de ionômero de vidro (Alhadainy et al., 1998; Makkawy, 1998b; Ruddle, 2002; Ferris; Baumgartner, 2004; Hashem; Hassanien, 2008; Katge; Shivasharan; Patil, 2016) e Super EBA (ácido etoxibenzóico) (Gartner; Dorn, 1992; Torabinejad et al., 1993; Torabinejad et al., 1995; Ruddle, 2002; Ferris; Baumgartner, 2004; Hashem; Hassanien, 2008; El Tawil et al., 2011). Entretanto, estes materiais têm apresentado deficiências quanto à infiltração, solubilidade, biocompatibilidade, manipulação e toxicidade, além de intolerância à umidade (Torabinejad et al., 1993; Ford et al., 1995; Ferris; Baumgartner, 2004; Chang et al., 2005; Xavier et al., 2005; Bidar et al., 2011; Nishtha et al., 2014). 
No início da década de 1990, foi desenvolvido na Universidade de Loma Linda (USA) o agregado de trióxido mineral (MTA), um derivado do cimento de Portland, (Estrela et al., 2000; Camilleri et al., 2005; Hashem; Hassanien, 2008; Nishtha et al., 2014), com o objetivo específico de selar as comunicações entre o sistema de canais radiculares e a superfície dentária externa, como também para o tratamento de perfurações radiculares acidentais ou resultantes de processos de reabsorção externa ou interna (Jew, et al., 1982; Benenati et al.,1986; Sinal et al., 1989; Lee et al., 1993; Torabinejad et al., 1993; Alhadainy; Abdalla, 1998; Schwartz et al., 1999; Torabinejad; Chivian, 1999; De-Deus et al., 2006; Parikrokh; Torabinejad, 2010a; Parikrokh; Torabinejad, 2010b; De Rossi et al., 2014). Posteriormente, este material passou a ser utilizado com sucesso em cirurgias endodônticas, proteção pulpar direta, pulpotomias, apicificação e apicigênese (Bernabé et al., 2002; Parikrokh; Torabinejad, 2010b; Kenchappa et al., 2015; Daltoé et al., 2016).

O MTA apresenta em sua composição, silicato tricálcico, silicato dicálcico, alumínio tricálcico, tetracálcio de alumínio ferroso, óxido de bismuto e sulfato de cálcio hidratado, além de pequenas quantidades de outros óxidos minerais, como por exemplo, ferro, alumínio e magnésio, que diferem entre os fabricantes (Holland et al., 2001; Salako et al., 2003; Asgary et al., 2008; Kuratate et al., 2008; Hasheminia et al., 2010; Silva Neto et al., 2010; Nishtha et al., 2014). Este material é composto por um pó de minúsculas partículas hidrofílicas que tomam presa em contato com a umidade. Esta hidratação produz um gel coloidal com pH de aproximadamente 12,5 , que se solidifica numa estrutura rígida dentro de aproximadamente 4 horas (Dammaschke et al., 2005; Aggarwal et al., 2013). É mais radiopaco que a dentina, possui baixa solubilidade e após 21 dias atinge uma força compressiva de $70 \mathrm{MPa}$, podendo receber materiais restauradores sobre ele, sem afetar a estrutura dental (Broon et al., 2006; Moore; Fitz-Walter; Parashos, 2009).

Em função de sua alta alcalinidade, o MTA apresenta atividade antimicrobiana (Torabinejad et al., 1995; Estrela et al., 2000). Além disso, apresenta compatibilidade tecidual (Torabinejad et al., 1995; Koh et al., 1997; Torabinejad et al., 1998; Keiser et al., 2000; Moretton et al., 2000; Holland et al., 2001; De- Deus et al., 2005; Reston; Souza Costa, 2009; Simsek et al., 2015), adequado selamento (Torabinejad et al., 1993; Torabinejad et al., 1995; Bates et al., 1996; Nakata et al., 1998; Queiroz et al., 1998; Aqrabawi, 2000; Ibricevic; Al-Jameq, 2003), não sofre 
alterações na presença de sangue (Torabinejad et al., 1994), não apresenta potencial mutagênico (Kettering; Torabinejad, 1995; Pellicioni et al., 2004; Zeferino et al., 2010; Naghavi et al., 2014; Gomes-Cornélio et al., 2016), possui baixa citotoxicidade (Torabinejad et al., 1995; Keiser et al., 2000; Naghavi et al., 2014), apresenta capacidade cementogênica (Morandi, 1999; Holland et al., 2001; Bogen; Kim; Bakland, 2008; Hashem; Hassanien, 2008; Gomes-Cornélio et al., 2016b) e estimula a neoformação óssea (Do Nascimento et al., 2008) e de tecido mineralizado (Abedi et al., 1996; Holland et al., 2001; Reston et al., 2009; Simsek et al., 2015), que por sua vez leva à regeneração do ligamento periodontal no local da lesão (Schwartz et al., 1999; Torabinejad; Chivian 1999; Roberts et al., 2008). Além disso, não altera a citomorfologia de células tipo osteoblastos (Koh et al., 1998) e nem sua aderência (Favieri et al., 2008) e estimula a supra regulação de citocinas envolvidas na remodelação óssea. Além dessas vantagens, o MTA favorece ainda uma menor reposta inflamatória quando comparado ao hidróxido de cálcio e a formação de pontes de tecido mineralizado com estrutura mais regular (Moghaddame-Jafari et al., 2005; Takita et al., 2006; Hashem; Hassanien, 2008; Nair et al., 2008; Bogen; Kim; Bakland, 2008; Reston et al., 2009; Paranjipe et al., 2010; Gomes-Cornélio et al., 2016).

Entretanto, este material apresenta desvantagens que incluem uma potencial alteração de cor do elemento dental e da gengiva (Camilleri, 2006; Nishtha et al., 2014) em decorrência do óxido de ferro, muito embora o MTA na cor branca tenha atenuado este problema sem comprometer suas características (Camilleri, 2006; Nishtha et al., 2014); dificuldade de manipulação, tempo de presa prolongado (Chang, 2012) e ausência de um solvente conhecido para o mesmo, gerando, portanto, uma dificuldade de remoção após seu endurecimento, caso haja necessidade (Torabinejad et al., 1995; Shipper et al., 2004; Camargo et al., 2007; Coon et al., 2007; Gorduysus et al., 2007; Hakki et al., 2009; Perinpanayagam et al., 2009; Parirokh; Torabinejad, 2010; Leiendecker et al., 2012; Aggarwal et al., 2013). Além disso, há evidências de que o óxido de bismuto, utilizado como radiopacificador, diminua a estabilidade mecânica (Graziottin-Soares et al., 2014; da Fonseca et al., 2015) e aumente a porosidade do MTA (Coomaraswamy et al., 2007; da Fonseca et al., 2015), podendo ainda inibir a proliferação celular (Camilleri et al., 2004). 
Como o MTA é um cimento derivado do cimento Portland, ambos apresentam em sua composição química metais pesados, como chumbo, cromo e arsênio. $\mathrm{O}$ arsênio pode atingir níveis superiores ao limite de segurança estabelecido pela ISO 9917-1/2007 (Schembri et al., 2010), e quando absorvido pelo organismo, é distribuído para os ossos, unhas, cabelos, pulmão e circulação sanguínea, podendo aumentar o risco de câncer, principalmente em gestantes e crianças (Cui et al., 2013; Farzan et al., 2013). Ainda, a presença do alumínio em sua fórmula pode aumentar o risco de doenças degenerativas como Parkinson e Alzheimer (Camilleri, 2011).

Segundo Malkondu e colaboradores (2014) a biocompatibilidade de um material odontológico é o principal fator a ser considerado quando o mesmo for utilizado em proteção pulpar, perfuração de furca ou obturação retrógrada. Desta forma, nos últimos anos, foi desenvolvido um material à base de silicato tricálcio, com o objetivo de reunir propriedades como ação antimicrobiana semelhante ao hidróxido de cálcio e capacidade seladora satisfatória, sem a presença de metais pesados, sabidamente deletérios ao organismo (Wang et al., 2012).

O mercado europeu lançou no ano de 2009 um cimento à base de silicato tricálcico denominado Biodentine ${ }^{\mathrm{TM}}(\mathrm{BD})$, patenteado pelo laboratório francês Septodont (St-Maur-des-Fossés - França) e disponibilizado em janeiro de 2011 (Kenchappa et al., 2015). A apresentação comercial deste material é sob forma de pó e líquido. O pó encontra-se contido em cápsulas de pó de silicato tricálcico, silicato dicálcico, carbonato de cálcio e óxido de zircônio como radiopacificador, pois tem sido demonstrado que o óxido de zircônio adicionado ao cimento à base de silicato de cálcio fornece melhores propriedades físico-químicas e melhor resposta biológica em comparação ao óxido de bismuto (Camilleri; Cutagar; Mallia, 2011; Silva et al., 2014; da Fonseca et al., 2015). O líquido é à base de água, que contém o cloreto de cálcio como acelerador de presa e um polímero hidrossolúvel (policarboxilato) (Han; Okiji, 2011; Camilleri et al., 2012; da Fonseca et al., 2015), que mantém uma boa capacidade de escoamento.

A BD apresenta propriedades superiores ao MTA em relação à biocompatibilidade e bioatividade (Koube et al., 2013; Daltoé et al., 2016), maior resistência à compressão e tempo de presa mais rápido, em função da adição do carbonato e do sulfato de cálcio à sua fórmula (Zhao et al., 2005; Camilleri et al., 2013; Silva et al., 2014; da Fonseca et al., 2015). Em relação à composição química, 
embora ambos os materiais sejam à base de silicato tricálcico, a ausência do aluminato na $\mathrm{BD}$, além de favorecer o menor tempo de trabalho, evita potenciais riscos à saúde (Laurent et al., 2008; Wang et al., 2008; Biodentine Active Biosilicate Technology Scientific File, Septodont, 2010; Wongkornchaowalit; Lertchirakarn, 2011; Camilleri et al., 2012; Camilleri et al., 2013; Kenchappa et al., 2015). Além disso, este material apresenta propriedades físicas suficientes para ser utilizado como material obturador de canais radiculares (Wang et al., 2008; Kenchappa et al., 2015), apresenta facilidade de inserção e boa bioatividade frente aos fluidos bucais (Camilleri et al., 2013; Kenchappa et al., 2015) possibilitando a deposição de hidroxiapatita em sua superfície, além de degradação in vitro aceitável (capacidade de substituição do cimento por tecido natural) (Zhao et al., 2005). Ainda, a BD apresenta estabilidade de cor (Vallés et al., 2013; Kenchappa et al., 2015), não é genotóxica (Opacic-Galic et al., 2013; Kenchappa et al., 2015) e possui baixa citotoxicidade (Laurent et al., 2008; Kenchappa et al., 2015) mantendo assim, a viabilidade dos fibroblastos gengivais, semelhante ao que é observado após o uso do MTA (Zhou et al., 2013; Kenchappa et al., 2015).

As indicações da BD segundo o fabricante incluem uso para reparação de perfurações radiculares (Camilleri et al., 2013; Grech, 2013a), perfurações de furca, reabsorções internas e externas, apicificação e retrobturação em cirurgia paraendodôntica, uso em procedimentos endodônticos conservadores, como a pulpotomia e proteção pulpar direta (Shayegan et al., 2008; Laurent et al., 2012; Nowicka et al., 2013; De Rossi at al., 2014; Malkundu et al., 2014), restauração de lesões cervicais e radiculares profundas, além de restauração de lesões de cárie profundas e extensas, como substituta da dentina (Laurent et al., 2008; Malkondu et al., 2104; Kenchappa et a., 2015).

Embora a BD seja indicada para o reparo de perfurações de furca, até o presente momento, não há estudos publicados na literatura específica, avaliando seus efeitos biológicos, quando empregada com esta finalidade. 

2. PROPOSICCÃO 



\section{PROPOSIÇÃO}

O presente estudo tem por objetivo avaliar a resposta dos tecidos perirradiculares de dentes de cães, após perfuração de furca intencional e selamento com BD ou MTA, por meio de análise radiográfica, histopatológica, imuno-histoquímica e imunofluorescência indireta. 

3. Material e Métodos 



\section{MATERIAL E MÉTODOS}

\subsection{Animais de Experimentação}

A princípio o presente estudo foi submetido à apreciação e subsequente aprovação pela Comissão de Ética no uso de Animais da Faculdade de Odontologia de Ribeirão Preto da Universidade de São Paulo (CEUA/FORP-USP) processo $\mathrm{n}^{\circ}$ 2014.1.76.58.4 (Anexo A).

Foram utilizados na pesquisa 3 cães da raça Beagle, provenientes de uma mesma ninhada, de ambos os gêneros, com 12 meses de idade e peso médio de 15 Kg. Durante todo o experimento, os animais foram mantidos no Biotério II da FORP. USP, alojados em baias individuais, sob os cuidados de um médico veterinário. $A$ dieta dos animais incluiu ração e água à vontade. Antes do início dos experimentos, os animais receberam vermífugos (Drontal Puppy - Bayer - São Paulo -SP - Brasil), na dosagem de 1 comprimido a cada $10 \mathrm{~kg}$ de peso do animal, além de vitaminas (Glicopan Pet - Vetnil Indústria e Comércio de Produtos Veterinários Ltda.- Louveira - Brasil), vacina anti-rábica (Rai-Vac I- Fort Dodge - Campinas -SP - Brasil) e vacina polivalente (Duramune ${ }^{\circledR}$ - Boehringer Ingelheim) em 3 doses, com 3 semanas de intervalo entre cada aplicação. Caso apresentassem gengivite e/ou cálculo gengival, receberiam profilaxia, raspagem, alisamento e polimento coronário, seguido da aplicação de digluconato de clorexidina a 0,12\% (Faculdade de Ciências Farmacêuticas de Ribeirão Preto - Ribeirão Preto - SP - Brasil).

Todos os cuidados com os animais de experimentação seguiram as Normas e Princípios Éticos Adotados pela CEUA/FORP-USP e as Resoluções Normativas do Conselho Nacional de Controle de Experimentação Animal (CONCEA), regulamentados pela Constituição Federal Brasileira na Lei $n^{0} 11.794$, de 8 de outubro de 2008.

Os animais foram acompanhados por um período de 120 dias (Zhu et al., 2003; Al-Daafas e Al-Nazhar, 2007; Silva Neto et al., 2010; Silva Neto et al., 2012), visando restringir o número de animais ao mínimo indispensável para obtenção de resultados conclusivos, em atendimento às recomendações do CEUA/FORP-USP e da Lei $n^{\circ} 11.794$ (Art. 11, $\$ 4^{\circ}$ ). 


\subsection{Procedimentos Operatórios}

Foram utilizados os $2^{\text {os }}$ e $3^{\text {os }}$ pré-molares superiores e os $2^{\text {os }}, 3^{\text {os }}$ e $4^{\text {os }}$ prémolares inferiores permanentes, totalizando 30 dentes. Todos os dentes apresentavam coroas hígidas e 2 raízes com 2 canais radiculares separados (mesial e distal), retos e com rizogênese completa, evidenciados após avaliação de radiografia periapical inicial.

Os dentes foram distribuídos em 3 grupos: experimental, controle negativo e controle positivo, de acordo com o material utilizado para selamento após a perfuração de furca. No Grupo Experimental ( $n=14$ dentes) foi utilizada a BD, no Grupo Controle Negativo ( $\mathrm{n}=10$ dentes) o MTA branco; e no Grupo Controle Positivo ( $n=6$ dentes) a guta percha.

Para que todas as variáveis fossem testadas em um mesmo animal, e em diferentes quadrantes, cada hemiarco recebeu um material em sistema de rodízio, distribuído ao acaso. A composição dos materiais utilizados e seus fabricantes estão listados na Tabela 1. As instruções de manipulação dos materiais, assim como suas indicações e contraindicações, de acordo com os respectivos fabricantes estão nos anexos B e C.

Tabela 1 - Materiais utilizados, composições e fabricantes.

Material

Composição

\section{Fabricante}

Pó: $\quad$ Silicato tricálcico

Silicato dicálcico

Carbonato de cálcio

Biodentine $^{\mathrm{TM}}$

Óxido de cálcio

Óxido de ferro

Óxido de zircônio

Septodont (SaintMaurdes Fosses - França)

Líquido: Cloreto de cálcio

Polímero hidrossolúvel

Pó: $\quad$ Cimento Portland $(75 \%)$

Óxido de bismuto (20\%)

Sulfato de cálcio dihidratado (5\%)

Silicato tricálcico

Silicato dicálcico

Aluminato tricálcico

Dentsply Tulsa Dental

(Johnson City - TN - EUA)

Aluminato férrico tetracálcico

Líquido: Água 
Para a realização dos procedimentos operatórios foi efetuada a anestesia inalatória, sob os cuidados de um médico veterinário. Na fase de tranquilização, os animais foram pré-anestesiados por meio de injeção por via intramuscular de acepromazina (Acepran a 0,2\% - Univet SA. - São Paulo/SP- Brasil), na dosagem de $0,05 \mathrm{mg} / \mathrm{kg}$ de peso, 15 minutos antes do ato operatório. Na fase de indução foi aplicado zolazepam (Zoletil@ 50 Virbac do Brasil -- São Paulo/SP - Brasil), na dosagem de $10 \mathrm{mg} / \mathrm{kg}$ de peso, por via endovenosa, para posterior passagem da sonda endotraqueal, necessária para a realização da anestesia inalatória. Após a intubação com sonda endotraqueal, a fase de manutenção da anestesia foi realizada com isoflurano (Baxter Hospitalar Ltda, São Paulo/SP - Brasil), na concentração de 1,5 a 2,5\%, juntamente com oxigênio, utilizando o aparelho para anestesia inalatória (Takaoka KT-20 - Biocom Tecnologia - São Paulo - SP - Brasil), até indução do efeito. Durante todo o ato operatório, os animais foram mantidos com solução isotônica de cloreto de sódio a 0,9\% (Glicolabor Indústria Farmacêutica Ltda. Ribeirão Preto - SP - Brasil), sob monitoramento cardiorrespiratório realizado com auxílio de oxímetro de pulso veterinário (Edan ZEH100B -Sistem Biomédica Yucatan - México). As dosagens dos fármacos utilizados nos protocolos préoperatório, operatório e pós-operatório seguiram o Guia Terapêutico de Bretas, 2007.

O exame radiográfico periapical dos dentes foi realizado com filmes periapicais $\mathrm{n}^{\circ} 2$, ultrarrápidos (Eastman Kodak Company - Rochester -NY- EUA), pela técnica da bissetriz, utilizando aparelho de raios-X odontológico (Heliodent- Siemens -NY-EUA), com $60 \mathrm{kVp}$ e $10 \mathrm{~mA}$ e tempo de exposição de 1 segundo. As radiografias foram reveladas em câmara escura pelo método tempo/temperatura.

Todo o instrumental utilizado nos procedimentos operatórios foi esterilizado em autoclave a $121^{\circ} \mathrm{C}$, por 20 minutos, e os procedimentos operatórios realizados por um único profissional, cirurgião-dentista, com ampla experiência em experimentação animal. Após a realização de profilaxia e raspagem coronária, procedeu-se ao isolamento do campo operatório com grampo e dique de borracha, seguidos de antissepsia do mesmo com digluconato de clorexidina a 2,0\% (Faculdade de Ciências Farmacêuticas de Ribeirão Preto - Ribeirão Preto - São Paulo - Brasil). Para a abertura coronária foram utilizadas pontas esféricas diamantadas n¹012 (K.G. Sorensen - São Paulo -SP - Brasil) montadas em motor 
de alta rotação, refrigeradas com ar/água, complementadas com pontas diamantadas cônicas de extremidade inativa ( $n^{\circ} 3083$ - KG Sorensen - São Paulo SP - Brasil), na face oclusal dos dentes. A cada 3 preparos cavitários uma nova ponta foi utilizada para assegurar a eficiência do corte e evitar possível aquecimento.

Após a cirurgia de acesso e a determinação do comprimento real de trabalho (CRT), a polpa foi removida com lima Hedstroen (Dentsply/Maillefer - Oklahoma USA) e os canais radiculares instrumentados com limas de níquel-titânio do Sistema ProTaper Universal (Dentsply/Maillefer - Oklahoma - USA), acionadas pelo motor XSmart (Dentsply/Maillefer - Oklahoma - USA), de acordo com o calibre do canal radicular. A irrigação dos canais radiculares foi efetuada com hipoclorito de sódio a $1 \%$, por meio de uma agulha convencional (Max-i-Probe, Dentsply/Tulsa Dental, York - PA) e pressão positiva, com volume de $3,6 \mathrm{~mL}$ a cada troca de instrumento. A irrigação final foi realizada utilizando EDTA, 17\% (Biodinâmica - Ibiporâ - PRBrasil), por 30 segundos, seguidos de abundante irrigação com hipoclorito de sódio a $1 \%$.

Os canais radiculares foram secos utilizando-se pontas de papel absorvente esterilizadas, seguido da obturação dos canais com cones de guta percha e cimento AH-Plus (Dentsply - De Trey, Konstanz - Germany), por meio da técnica de condensação lateral.

Uma perfuração padronizada foi efetuada intencionalmente no centro do assoalho da câmara pulpar, com uma ponta esférica diamantada 1012 (KG Sorensen - São Paulo -SP - Brasil), tendo esta perfuração o diâmetro desta ponta diamantada, tanto no grupo experimental quanto nos grupos controle. Para controlar o sangramento, foram utilizadas mechas de algodão esterilizadas. A cada 3 perfurações foi utilizada uma nova ponta.

Após a confecção da perfuração, esta foi preenchida com os diferentes materiais. O líquido foi incorporado à cápsula de BD contendo pó e, em seguida a cápsula foi inserida em agitador de cápsulas (Amalgamador - Ultramat S Capsular Digital - SDI - Southern Dental Industries Ltd. Victoria - Austrália) durante 30 segundos. O material foi aplicado sobre a lesão de furca com o auxílio de uma cureta, sem pressão excessiva, aguardando o tempo de presa de 12 minutos. A manipulação do MTA foi realizada em uma placa de vidro esterilizada, sendo o pó incorporado ao líquido até a obtenção de uma pasta espessa. Posteriormente, o material foi aplicado sobre a lesão de furca com o auxílio de uma cureta, sem 
pressão excessiva, aguardando o tempo de presa inicial de 12 minutos. Nos espécimes do grupo controle positivo, a perfuração de furca foi preenchida com guta percha em forma de bastão (Odahcan Maillefer - Dentsply - Teresopolis/ RJ Brasil). Em seguida, em todos os grupos, as cavidades foram restauradas com amálgama de prata (Sybraloy - Kerr Corporation, Orange - CA). Ao final dos procedimentos operatórios, uma segunda radiografia periapical de cada dente foi realizada.

Os procedimentos pós-operatórios constaram de acompanhamento do animal até sua completa recuperação anestésica, seguida de exame físico geral, observação da coloração da mucosa e auscultação. Além disso, foi administrado como fármaco analgésico o cloridrato de tramadol (Tramal $50 \mathrm{mg} / \mathrm{mL}$ - União Química Farmacêutica Nacional - Pouso Alegre/MG - Brasil) na dose de 3mg/kg, via subcutânea, de 8/8 horas, durante 3 dias. Os animais foram acompanhados durante todo o período experimental com a finalidade de observar possíveis mudanças de comportamento, de hábitos alimentares, presença de processos inflamatórios e/ou infecciosos dos tecidos, ou outras alterações.

Decorridos 120 dias do experimento, foram realizadas radiografias periapicais finais, e os animais foram submetidos à eutanásia, de acordo com as Diretrizes da Prática de Eutanásia do CONCEA do Ministério da Ciência e Tecnologia. Inicialmente, foi realizada anestesia por meio de injeção por via endovenosa de acepromazina (Acepran a 0,2\%), na dosagem de 0,2 mg/kg de peso. Após 15 minutos, foi efetuada a anestesia com Tiopental (Thionembutal - Abbot Laboratórios do Brasil Ltda. - Rio de Janeiro - RJ - Brasil) endovenoso, na dosagem de $25 \mathrm{mg}$ ou mais $/ \mathrm{kg}$ de peso, na concentração de $50 \mathrm{mg} / \mathrm{mL}$. Em seguida, foi efetuada a eutanásia com cloreto de potássio a $20 \%$, via endovenosa, na dosagem de $100 \mathrm{mg} / \mathrm{kg}$ de peso, injetado lentamente. A confirmação da eutanásia se fez por meio da verificação da parada cardiorrespiratória, pela ausência de movimento respiratório (apneia), ausência de batimentos cardíacos (assistolia) detectada com uso do estetoscópio ou doppler-ultrassom, ausência de pulsação, mucosas pálidas e perda de reflexo corneal. A seguir, as maxilas e mandíbulas foram removidas e submetidas ao processamento histotécnico. 


\subsection{Análise Radiográfica}

As imagens radiográficas (radiografia inicial, radiografia imediatamente após o selamento/restauração dos dentes e radiografia após 120 dias) foram avaliadas por 2 examinadores calibrados (Kappa > 0.8) sem conhecimento prévio do grupo a ser analisado. A avaliação dessas imagens foram realizadas no local correspondente à perfuração de furca, por meio da observação de deposição de tecido mineralizado, integridade da lâmina dura, áreas radiolúcidas sugestivas de rarefações ósseas interradiculares e áreas radiolúcidas sugestivas de reabsorções radiculares externas, com atribuição de escores para cada parâmetro avaliado (Silva et al., 2008), (Tabela 2).

Tabela 2 - Parâmetros e escores empregados para a análise radiográfica.

\begin{tabular}{cc} 
Parâmetros & Escores \\
\hline Deposição tecido mineralizado na área de & 0 : ausente \\
perfuração de furca & 1 : presente \\
& 0 : íntegra \\
Rarefação óssea inter-radicular & 1 : alterada \\
& 0 : ausente \\
Reabsorção radicular externa & $1:$ presente \\
& $0:$ ausente \\
\hline
\end{tabular}

\subsection{Processamento Histotécnico}

As maxilas e mandíbulas contendo os dentes foram removidas, dissecadas com o auxílio de um bisturi e seccionadas para obtenção de blocos individuais, compostos por dente e tecidos perirradiculares adjacentes. As peças foram submetidas à fixação em solução de formol tamponado a $10 \%$ por 72 horas, à temperatura ambiente. Em seguida, foram imersas em um recipiente de vidro contendo uma solução à base de EDTA (ácido etilenodiaminotetracético) composta de EDTA (93,05g - EDTA Disodium Salt Dihydrate - Merck - Darmstadt - Alemanha), glutaraldeído a 25\% (20mL - Glutaraldehyde 25\% Aqueous Solution - Mallinckrodt Chemicals - Phillipsburg - EUA), cacodilato de sódio a 98\% - solução tamponada pH 7,4 (280mL - Sigma Cacodylic acid - Sigma - St. Louis - EUA), água destilada 
(200mL) e hidróxido de sódio 0,1N (Hidróxido de Sódio p.a. - Casa da Química Ind. e Com. Ltda - Diadema - SP - Brasil) e submetidas à desmineralização, acelerada pelo forno de micro-ondas (Sharp Carousel - São Paulo - Brasil). Para a realização deste procedimento, o recipiente contendo as peças foi parcialmente imerso em outro recipiente de vidro contendo água e gelo, com o objetivo de retardar o aumento da temperatura e, consequentemente, incrementar o tempo de ação das micro-ondas. O forno de micro-ondas funcionou na frequência de trabalho de $2450 \mathrm{MHz}$, correspondendo a uma frequência de onda no vácuo de $12,2 \mathrm{~cm}$, potência máxima nominal de $700 \mathrm{~W}$, regulado em potência média/máxima na temperatura de $30^{\circ} \mathrm{C}$ para evitar alterações teciduais. As peças foram irradiadas por 10 minutos, com intervalos de 5 minutos entre as irradiações, por um período de 4 horas/dia. A cada 6 irradiações, as peças foram lavadas com solução tampão de cacodilato de sódio a $98 \%$ tamponado, $\mathrm{pH} 7,4$, sendo a solução à base de EDTA renovada. No intervalo entre os dias, o material permaneceu na solução desmineralizadora sem agitação, à temperatura ambiente.

O grau de descalcificação das estruturas mineralizadas foi testado por meio da penetração mecânica de uma agulha nos tecidos, para verificação da sua consistência, seguida de comprovação radiográfica da completa descalcificação, a qual ocorreu em aproximadamente 30 dias.

Posteriormente, as peças foram submetidas à técnica histológica de rotina, neutralizadas em solução de sulfato de sódio a 5\% (Sulfato de Sódio Anhidro - J.T. Baker, Xalostoc, México) por um período de 24 horas, lavadas em água corrente por 24 horas, desidratadas em concentrações crescentes de álcool (Álcool Etílico Absoluto Anhidro - J.T. Baker), diafanizadas em xilol (Xilol - Merck) e incluídas em parafina (Histosec Pastillen, Merck).

As peças contendo os dentes foram cortadas longitudinalmente em micrótomo (Leica RM2145 - Leica Microsystems GmbH, Weltzlar - Alemanha) no sentido mésio-distal, sendo obtidos cortes seriados com $5 \mu \mathrm{m}$ de espessura em toda extensão do dente. Todos os cortes obtidos foram observados em microscópio, entretanto, a análise histopatológica foi realizada em 3 lâminas de cada dente (média de 4 cortes seriados por lâmina), no local correspondente à perfuração de furca. 


\subsection{Análise Histopatológica}

As análises histopatológicas qualitativa, semi-quantitativa e quantitativa foram realizadas por 1 examinador experiente, sem conhecimento prévio do grupo a ser analisado. Os cortes foram avaliados no microscópio Axio Imager.M1 (Carl Zeiss Microlmaging $\mathrm{GmbH}$ - Gottingen - Alemanha), operando em luz convencional e de fluorescência (De Rossi et al., 2007). Para a avaliação em microscopia de fluorescência, as lâminas coradas com HE foram avaliadas com o filtro Alexa Fluor 488 (Carl Zeiss Microlmaging $\mathrm{GmbH}$ ), visando propor uma metodologia adicional para avaliar as respostas teciduais após a realização da perfuração de furca e selamento com os materiais testados.

$\mathrm{Na}$ análise histopatológica qualitativa foi avaliada a presença ou não de tecido mineralizado depositado no local da perfuração de furca e adjacente ao material.

A análise semi-quantitativa incluiu a atribuição de escores para os seguintes parâmetros: presença ou ausência de tecido mineralizado depositado, intensidade do processo inflamatório (ausente, suave, moderado, ou severo), contagem do número de células inflamatórias presentes na região central da perfuração de furca adjacente ao material de selamento ou ao tecido mineralizado recém-formado, numa área de aproximadamente $1 \mathrm{~mm}^{2}$ e reabsorção dos tecidos mineralizados. Os parâmetros e escores foram propostos com base na modificação de critérios descritos previamente (Albuquerque; Gominho; Santos, 2006; Leonardo et al., 2007; Nowicka et al., 2013) e estão listados na Tabela 3.

A análise histopatológica quantitativa da espessura de tecido mineralizado depositado na área de perfuração de furca foi realizada nos espécimes corados com HE em microscopia de luz fluorescente, utilizando videomicroscopia com o programa Axio Vision Rel. 4.8 (Carl Zeiss Microlmaging $\mathrm{GmbH}$ ), em conjunto com microscópio e câmera Axiocam (Carl Zeiss Microlmaging $\mathrm{GmbH}$ ), acoplados a um sistema de computador. Em cada corte, a espessura da ponte de tecido mineralizado foi determinada no sentido cérvico-oclusal, pela média de 3 medidas lineares, obtidas na região central da lesão de furca e em 2 regiões equidistantes, sendo o valor final expresso em milímetros $(\mathrm{mm})$. 
Tabela 3 - Parâmetros e escores empregados para a análise histopatológica semi-quantitativa.

\begin{tabular}{cc}
\hline Parâmetros & Escores \\
\hline Perfuração de furca & $0:$ ausente \\
1: parcial \\
2: presente \\
Deposição de Tecido Mineralizado Infiltrado & $0:$ ausente \\
Inflamatório & 1: suave \\
& 2: moderado \\
Reabsorção dos tecidos mineralizados & \\
(Dentina, Cemento, Osso) & 0: ausente \\
\end{tabular}

\subsection{Análise Imuno-Histoquímica - Análise da marcação para RANKL e Osteoprotegerina}

A partir dos resultados obtidos no estudo in vivo, foram realizados ensaios de imuno-histoquímica para os marcadores de mineralização: RANKL e osteoprotegerina (OPG).

As lâminas foram desparafinadas, hidratadas em série decrescente de álcoois e mantidas em salina fosfatada tamponada (PBS). A seguir, foram submetidas à recuperação dos epítopos antigênicos utilizando solução tampão de citrato de sódio ( $\mathrm{pH} 6,0$ ), aquecido em forno micro-ondas, por meio de 7 disparos de 12 segundos, com intervalos de 2 minutos entre cada disparo. Após a estabilização da temperatura, foram realizadas lavagens em PBS por 5 minutos $(3 x)$ e a peroxidase endógena foi bloqueada com peróxido de hidrogênio a 3\% por 40 minutos. Após, foram lavadas em PBS por 5 minutos $(3 x)$ e os sítios de ligação não específica foram bloqueados com albumina de soro bovino (Sigma-Aldrich, St. Louis, MO, EUA) a $5 \%$ por 60 minutos. A seguir, os tecidos foram incubados com os anticorpos primários para OPG (N-20): sc-8468, policlonal produzido em humanos, Santa Cruz Biotechnology, inc., EUA) e RANKL (N-19): sc-7628, policlonal produzido em camundongos, Santa Cruz Biotechnology, inc., EUA) a $4^{\circ} \mathrm{C}$, overnight. Em seguida, as lâminas foram lavadas e incubadas com anticorpos secundários biotinilados por 1 hora (anti-camundongo ou anti-coelho), lavadas em PBS, e incubadas com Diaminobenzidina (DAB, Sigma-Aldrich, St. Louis, MO, EUA) foi utilizada como substrato enzimático por 5 minutos; as lâminas foram lavadas em 
PBS, contra-coradas com hematoxilina de Harris por 15 segundos, lavadas com água destilada, desidratadas em concentrações crescentes de álcool e montadas em Entellan® (Merck,Darmstadt, Alemanha). Lâminas controle foram utilizadas para testar a especificidade da imunomarcação nas quais foi omitido o anticorpo primário e as lâminas foram incubadas com PBS.

A marcação positiva para RANKL/OPG foi avaliada por meio de scores ausente, suave, moderada ou severa. A porcentagem (frequência) de células coradas positivamente foi avaliada no espaço do ligamento periodontal adjacente ao tecido mineralizado formado na região de furca, na área central desse tecido com $1 \mathrm{~mm}^{2}$ de área.

\subsection{Análise de Imunofluorescência Indireta - Análise das células positivamente marcadas para o fator de transcrição RUNX2}

O ensaio de imunofluorescência indireta foi realizado para determinar a expressão de RUNX2 como fator de transcrição para a síntese de proteínas de mineralização e, portanto, indicador da diferenciação celular com fenótipo de mineralização.

As lâminas foram desparafinadas, hidratadas em série decrescente de álcoois e mantidas em salina fosfatada tamponada (PBS). Os tecidos foram submetidos à recuperação dos epítopos antigênicos utilizando solução tampão de citrato de sódio ( $\mathrm{pH}$ 6,0), aquecido em forno micro-ondas, por meio de 7 disparos de 12 segundos, com intervalos de 2 minutos entre cada disparo. A seguir foram lavadas em PBS por 5 minutos (3x) e em solução de borohidreto de sódio (Dinâmica Química Contemporânea Ltda., Diadema, SP, Brasil) a mg/mL por 15 minutos (3x). Os sítios de ligação não específica foram bloqueados com albumina de soro bovino (Sigma) a $5 \%$ por 60 minutos. A imunomarcação foi realizada utilizando anticorpo primário para RUNX-2 (ab23981, anticorpo policlonal produzido em coelhos, Abcam, Cambridge, MA, EUA) à $4^{\circ} \mathrm{C}$, overnight. Em seguida, as lâminas foram lavadas em PBS (3x) e incubadas com anticorpo secundário (anti-lgG de coelhos conjugado ao fluoróforo fluorosceína), por 1 hora, em câmera escura. As lâminas foram lavadas em PBS (3x) novamente e os núcleos foram marcados com 4',6-diamidino-2fenilindol (DAPI) $(0,5 \mu \mathrm{g} / \mathrm{mL})$ (Santa Cruz Biotechnology Inc., Dallas, TX, EUA) por 5 minutos. As lâminas foram montadas com Prolong Gold Antifade (Molecular Probes Inc., 
Eugene, EUA). Lâminas controle foram utilizadas para testar a especificidade da imunomarcação, nas quais o anticorpo primário foi omitido e as lâminas incubadas com PBS (Daltoé et al., 2016).

A porcentagem (frequência) de células positivamente marcadas foi avaliada na camada adjacente ao tecido mineralizado neoformado, no grupo experimental (BD), grupo controle negativo (MTA) e grupo controle positivo (guta percha). Primeiramente, as regiões foram fotografadas em microscopia de fluorescência em aumento de 20x, utilizando filtros DAPI e Alexa Fluor. Posteriomente, as imagens foram analisadas por meio do programa Image J (U.S. National Institutes of Health, Bethesda, MD, EUA) para obtenção da contagem de células positivamente marcadas, ajustando-se o "threshold" e com utilização da ferramenta "analyse particles", sendo que o valor do tamanho de partícula usado foi o tamanho médio do núcleo celular calculado previamente. Dessa forma, a contagem total de células marcadas foi realizada e os valores obtidos foram transformados em porcentagem. Os grupos foram comparados entre si pelo Teste de Kruskal Wallis com pós--teste de Dunn $(\alpha=0,05)$.

\subsection{Análise Estatística}

Os resultados radiográficos e histopatológicos do tecido mineralizado recémformado foram transformados em porcentagem e analisados pelo teste qui-quadrado e os resultados de reabsorção óssea (dados dicotômicos) foram analisados pelo teste exato do Fischer. Os resultados quantitativos foram analisados pelo teste D'Agostino \& Pearson para a normalidade dos dados. A espessura de tecido mineralizado e a área foram analisados pelo teste de Mann-Whitney e os resultados da contagem de células inflamatórias foram analisados por análise de variância unidirecional. Os dados quantitativos da intensidade de fluorescência RUNX2 foram analisados pelo teste de Kruskal-Wallis e pós-teste de Dunn. Todos os testes foram realizados usando o software estatístico Prism 6.0 e o nível de significância foi estabelecido em $5 \%$ para todas as análises. 

4. Resultados 



\section{RESULTADOS}

\subsection{Radiográficos}

Com relação à deposição de tecido mineralizado na área de perfuração de furca, observamos que houve diferença estatisticamente significante entre os 3 grupos analisados, onde a BD apresentou aproximadamente $90 \%$ de tecido mineralizado na área de perfuração de furca e o MTA aproximadamente $30 \%$ enquanto a guta percha apresentou $100 \%$ de ausência de deposição de tecido mineralizado (Gráfico 1) (Figura 1).

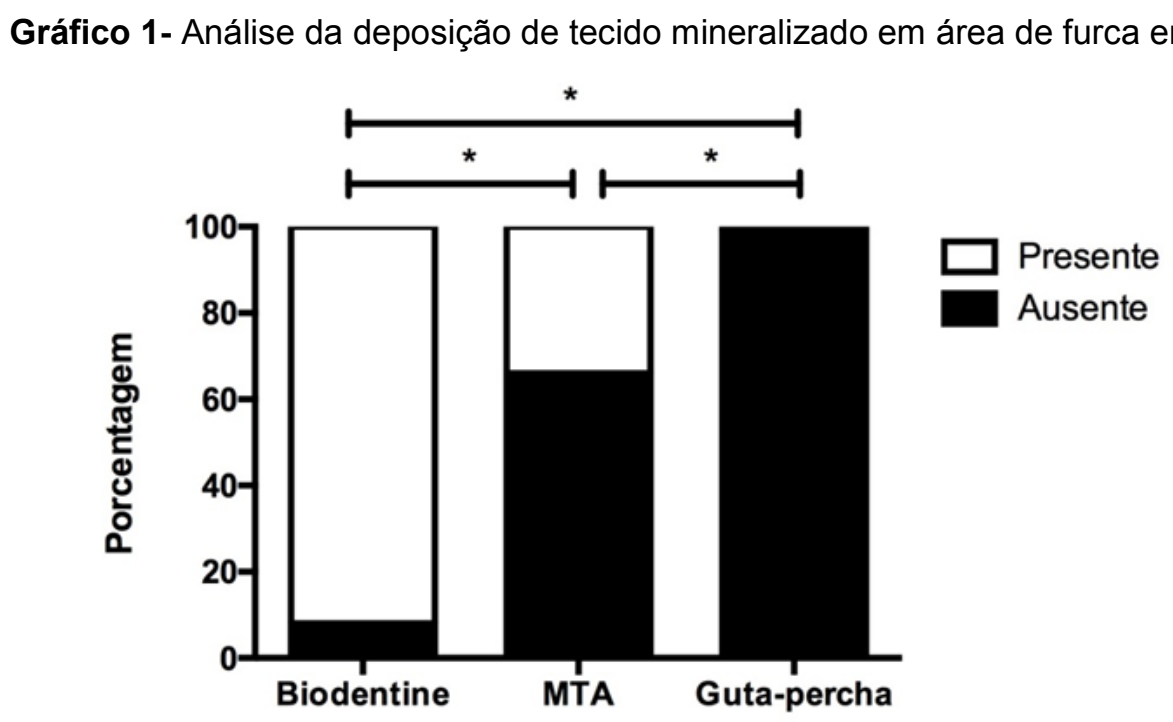

$\mathrm{Na}$ avaliação sobre a integridade da lâmina dura, observamos que houve diferença estatisticamente significante entre os 3 grupos analisados, onde a BD apresentou mais de $80 \%$ de integridade da lâmina dura e o MTA apresentou aproximadamente $20 \%$, enquanto a guta percha apresentou $100 \%$ de alteração na integridade da lâmina dura (Gráfico 2). 
Gráfico 2 - Análise da integridade da lâmina dura em \%.

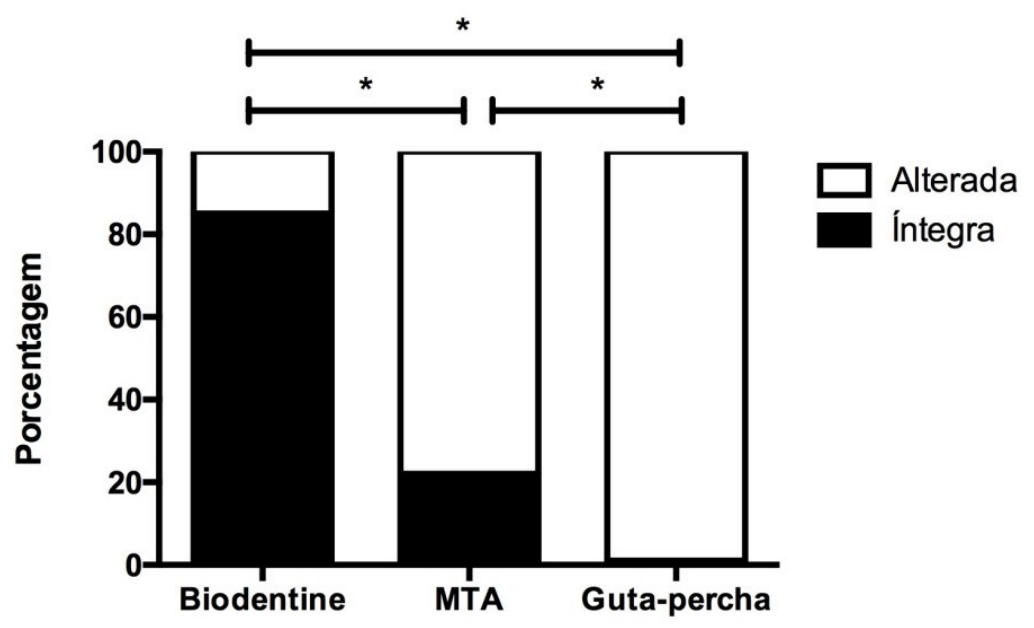

A respeito da presença de rarefação óssea, também houve diferença estatisticamente significante entre os 3 grupos analisados. No grupo da BD, mais de $80 \%$ das amostras se apresentaram isentas de rarefação óssea e no grupo do MTA, aproximadamente $40 \%$, enquanto no grupo da guta percha, $100 \%$ das amostras apresentaram rarefação óssea (Gráfico 3).

Gráfico 3 - Análise da presença de rarefação óssea em área de furca em \%.

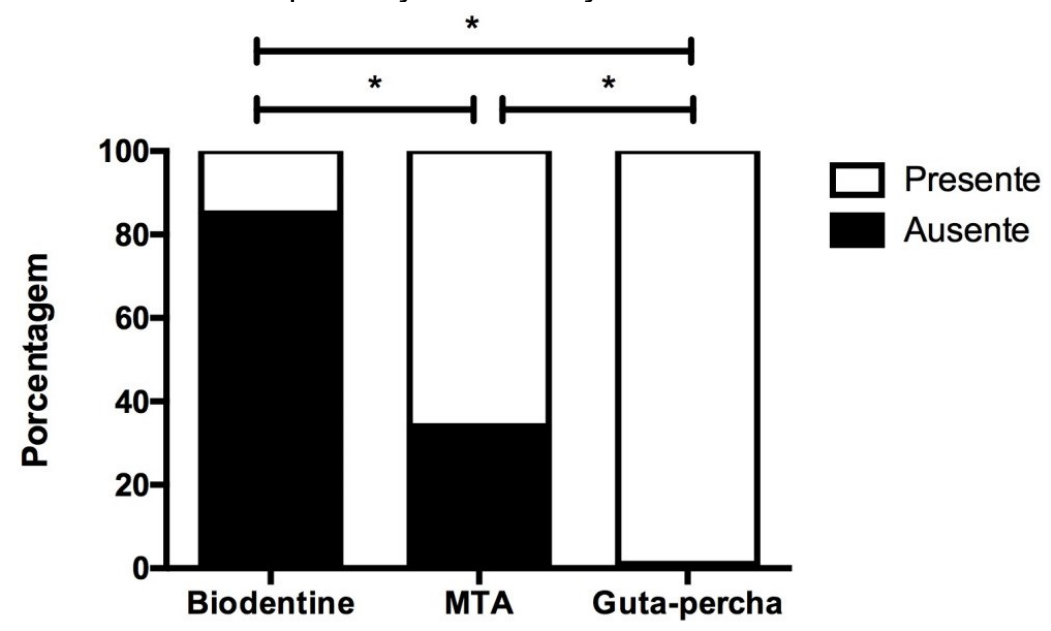

$\mathrm{Na}$ avaliação sobre a presença de reabsorção externa, houve diferença estatisticamente significante entre os 3 grupos analisados. No grupo da BD, nenhuma das amostras apresentou reabsorção e no grupo do MTA, 25\% das amostras apresentaram reabsorção, enquanto no grupo da guta percha, a reabsorção óssea esteve presente na totalidade das amostras (Gráfico 4). 
Gráfico 4 - Análise da presença de reabsorção externa em área de furca em \%.

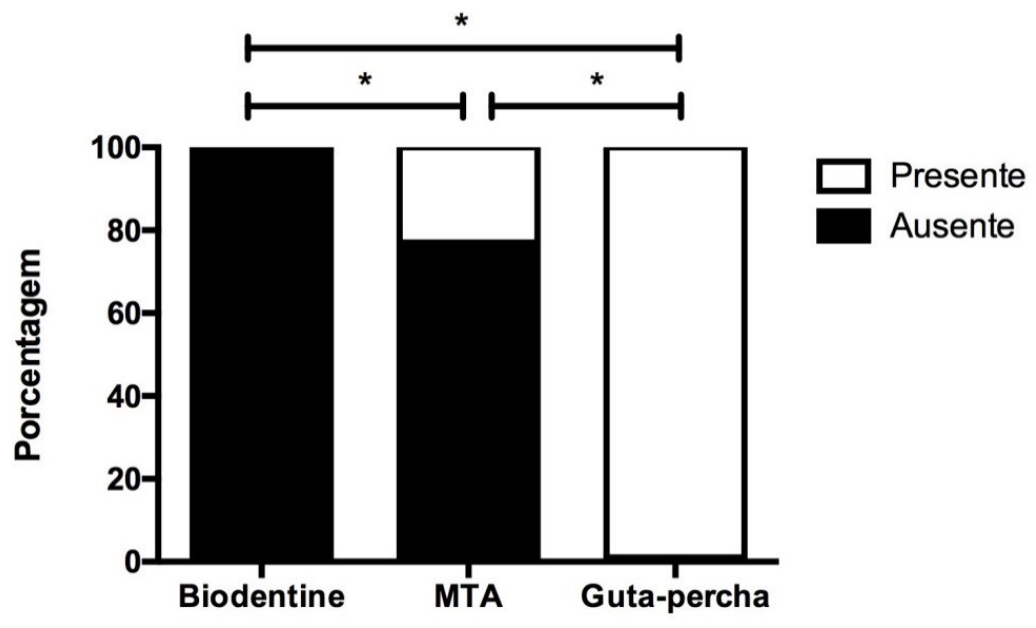


Figura 1- Imagem radiográfica representativa dos 3 grupos avaliados com os diferentes materiais seladores utilizados.

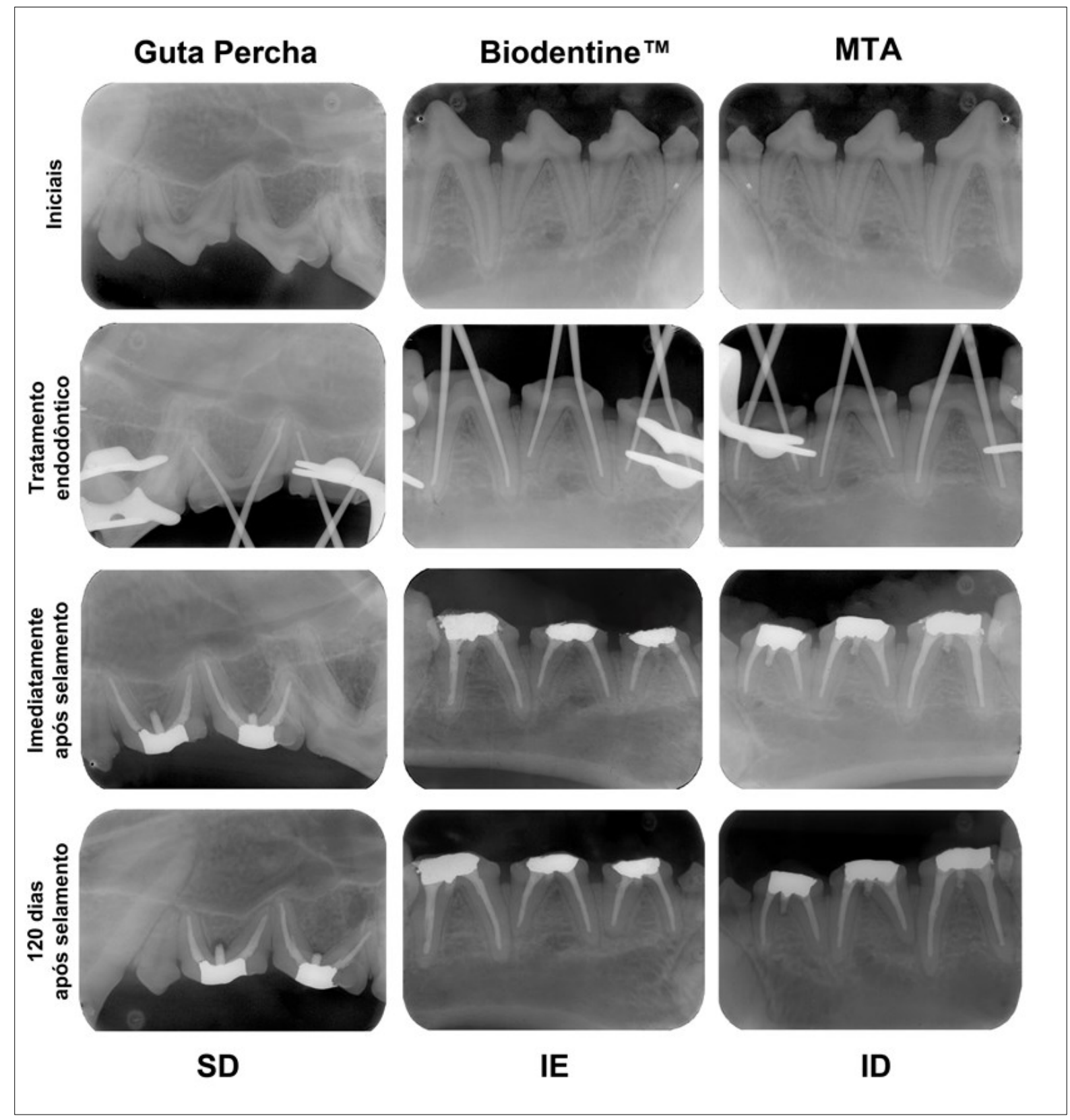


Gráfico 5 - Presença de tecido mineralizado (\%) (Teste qui-quadrado).

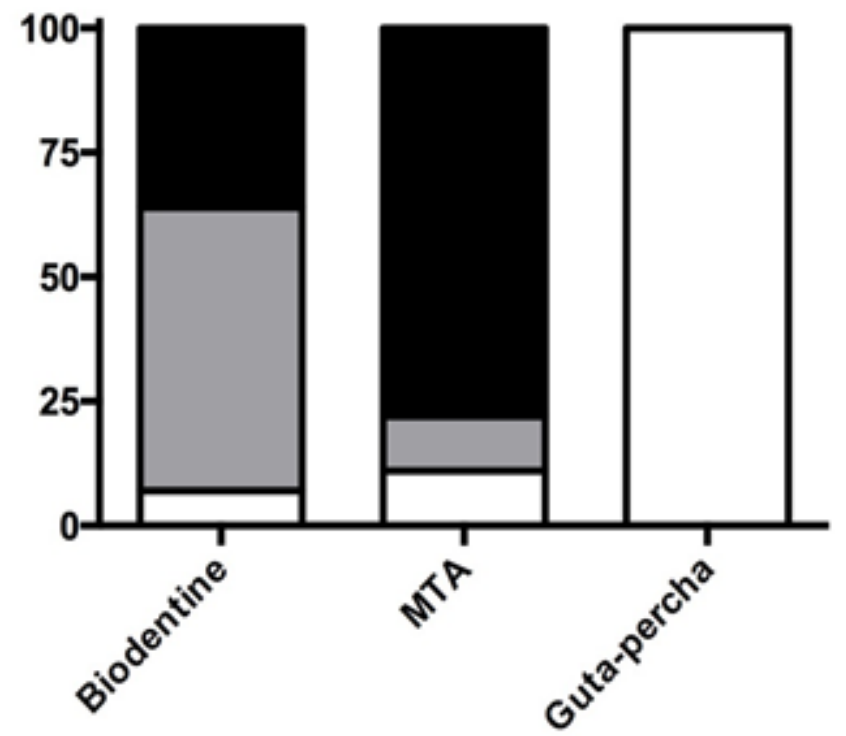

Quanto à análise semi-quantitativa (escores) de tecido mineralizado recémformado, a guta percha (controle positivo) foi significativamente diferente $(p<0,001)$ da BD e do MTA, que também diferiram um do outro $(p<0,001)$.

Dos 3 materiais, o MTA apresentou a maior frequência de selamento completo das perfurações de furca. Expressando estes resultados em porcentagem, BD apresentou $7,1 \%$ de ausência de tecido mineralizado formado, 57,1\% de tecido mineralizado selando parcialmente a perfuração de furca e 35,8\% de tecido mineralizado selando completamente a perfuração de furca. O MTA apresentou $11,1 \%, 11,1 \%$ e $77,8 \%$, respectivamente, e a guta-percha, apresentou $100 \%$ de ausência de formação de tecido mineralizado na área de perfuração de furca (Gráfico 5). Em suma, tanto o selamento com BD quanto com MTA induziram a reparação total ou parcial da perfuração de furca por meio da formação de tecido mineralizado em quase todas as amostras (92,9\% e 88,9\%), respectivamente, enquanto não se observou formação de tecido mineralizado no grupo controle positivo (guta-percha). No que diz respeito à área de tecido mineralizado recémformado, foi significativamente maior ( $p=0,0089$ ) no grupo MTA (Gráfico 6). Em relação à reabsorção óssea na região de perfuração de furca, a guta percha (controle positivo) foi significativamente diferente $(p<0,001)$ tanto da BD quanto do MTA, que foram semelhantes entre si $(p=1,00)$. Expressando esses resultados em porcentagem, tanto a BD quanto o MTA não apresentaram reabsorção óssea em $100 \%$ das amostras, enquanto no grupo controle positivo, a reabsorção óssea 
estava presente em 100\% das amostras (Gráfico 7). A contagem de células inflamatórias mostrou diferença significante apenas entre a BD e o grupo de controle positivo ( $p=0,0396)$, que apresentou um grande número de células inflamatórias. $O$ MTA apresentou valores intermediários e não diferiu significativamente dos outros grupos (Gráfico 8 e 9). A Figura 2 mostra resultados histopatológicos representativos dos grupos tratados com BD (A-C), MTA (D-F) e guta percha (G-I).
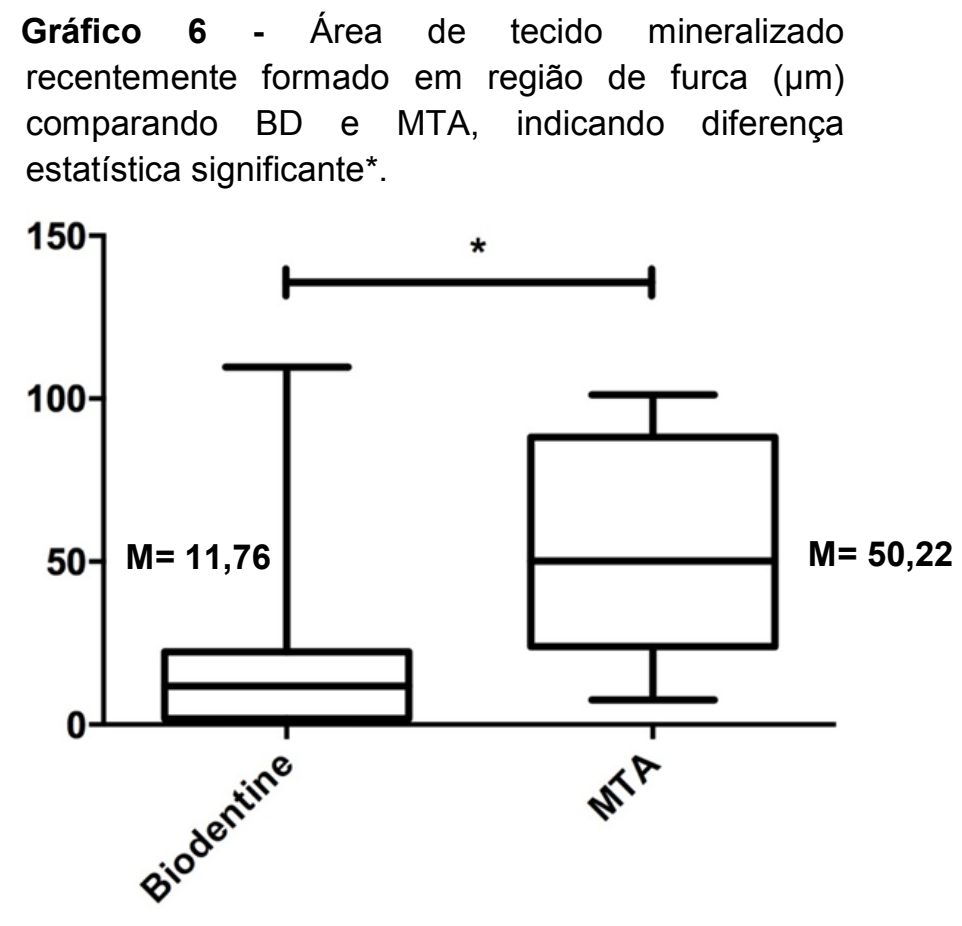

Gráfico 7 - Reabsorção óssea em área de furca (\%) (Teste qui-quadrado).

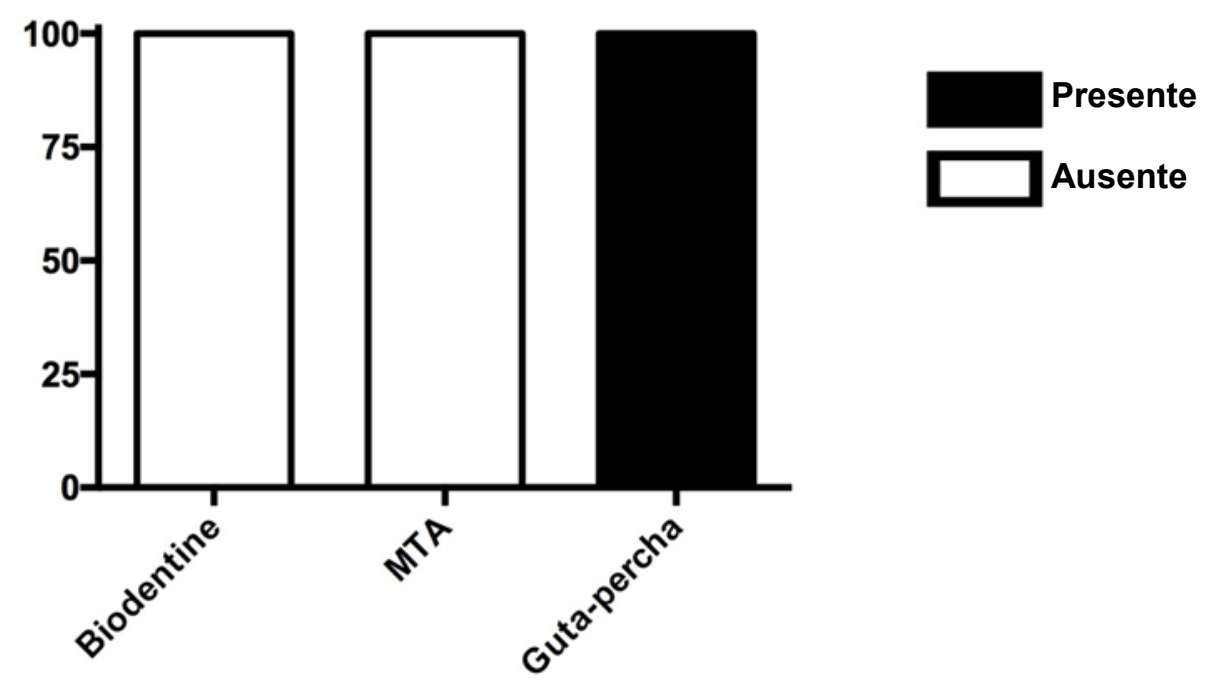


Gráfico 8 - Média de desvio padrão do número de células inflamatórias por $\mathrm{mm}^{2}$ nas perfurações de furca seladas com Biodentine, MTA e Guta Percha, indicando diferença estatísticamente significante *.

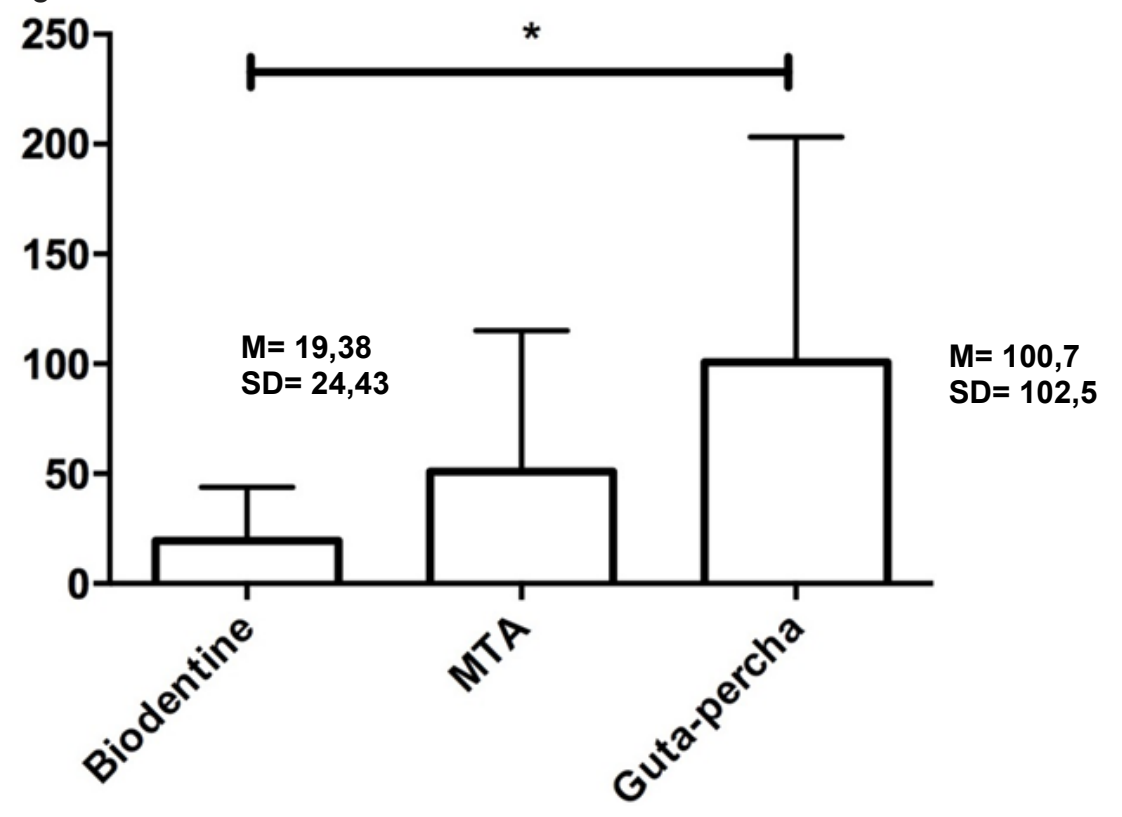

Gráfico 9 - Intensidade do infiltrado inflamatório (\%) (Teste qui-quadrado).

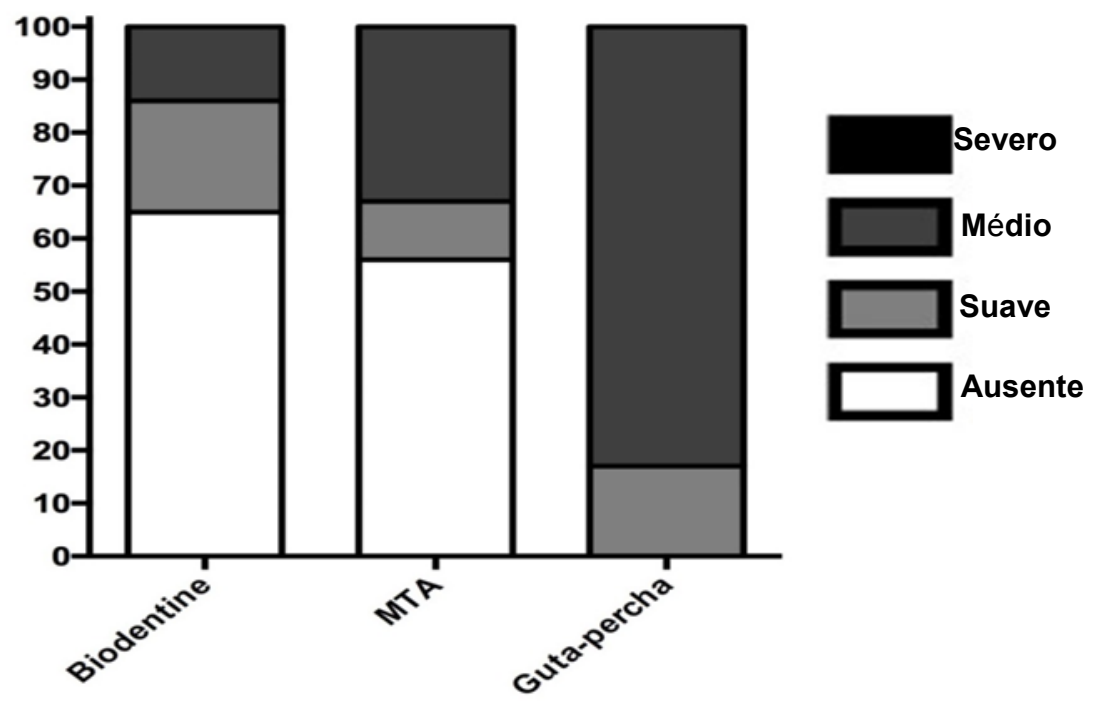

$\mathrm{Na}$ análise quantitativa, comparando os materiais para selamento da perfuração de furca, em relação à espessura do tecido mineralizado formado, o MTA induziu a formação de um tecido significativamente mais espesso $(p=0,0148)$ do que a BD (Gráfico 10). 
Gráfico 10 - Espessura do tecido mineralizado em área de selamento da perfuração de furca $(\mu \mathrm{m})$ indicando diferença estatística significante* entre BD e MTA.

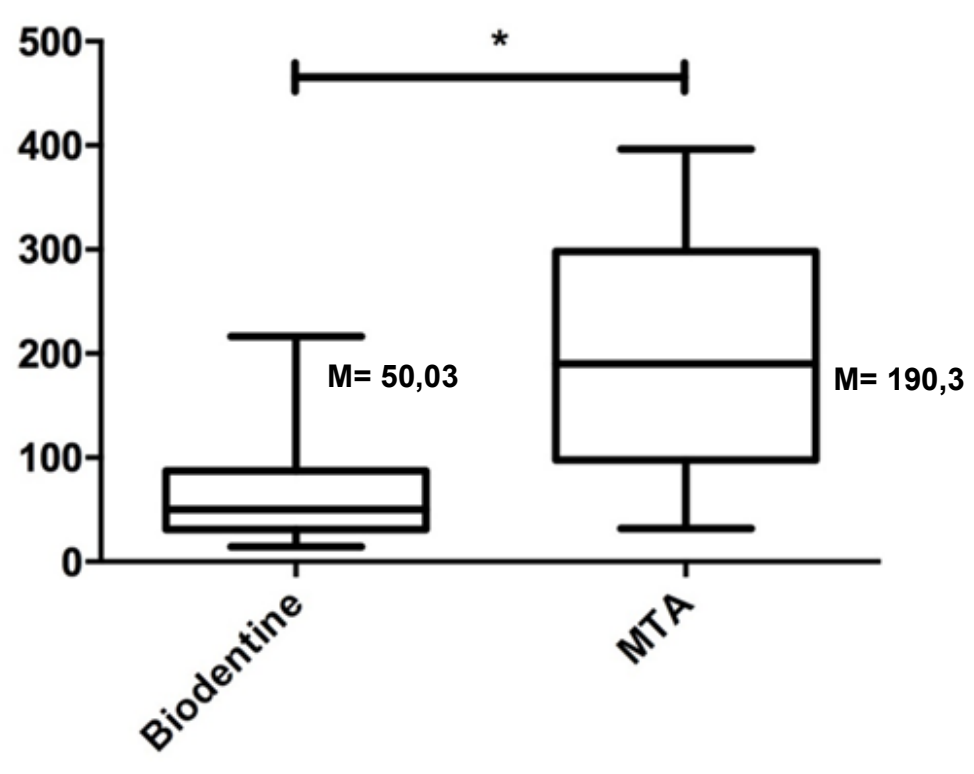


Figura 2- Fotomicrografias representativas de secções coradas com HE dos grupos tratados com BD (A-C), MTA (D-F) e guta-percha (G-I). A: Tecido mineralizado recém-formado selando completamente a perfuração da furca. B: Tecido mineralizado recém-formado em maior ampliação e reparação desta região. C: Ausência de células inflamatórias ou reabsorção do tecido ósseo. D: Tecido mineralizado selando completamente a perfuração da furca, com maior espessura e área. $\mathbf{E}$ : Tecido mineralizado recém-formado em maior ampliação, com maior espessura e área e reparação desta região. F: Poucas células inflamatórias e vários osteoblastos recuperando a superfície óssea, indicando um reparo contínuo. G: Ausência de formação de tecido mineralizado recém-formado no local da perfuração. H: Intenso infiltrado inflamatório. I: Lacunas de reabsorção óssea com osteoclastos em sua superfície. Barra de escala $=50 \mu \mathrm{m}$.
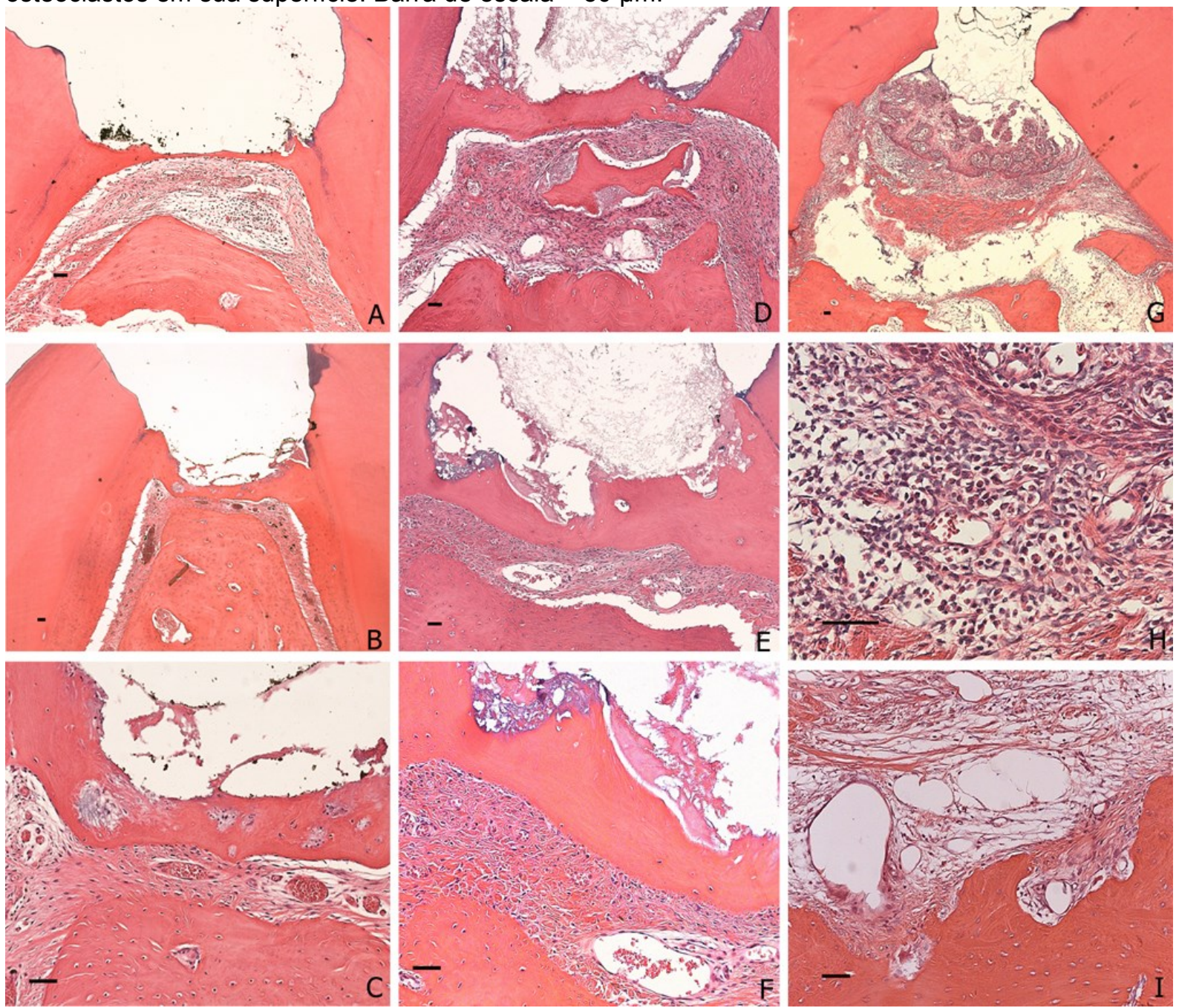



\subsection{Imuno-histoquímica - Análise da marcação para RANKL/OPG}

Em relação ao marcador que induz a formação de clastos, o RANKL, verificamos sua ausência completa em áreas de furca seladas com $B D$, e uma suave presença nas áreas de furca seladas com o MTA, quando comparada com a guta percha (Gráfico 11) (Figura 3). Quanto à presença de marcador contra a formação de osteoclastos, a OPG, observamos sua presença tanto na BD, quanto no MTA e no grupo controle positivo, a guta percha, embora, se apresentem em menos de $50 \%$ das amostras dos 3 grupos (Gráfico 12) (Figura 4).

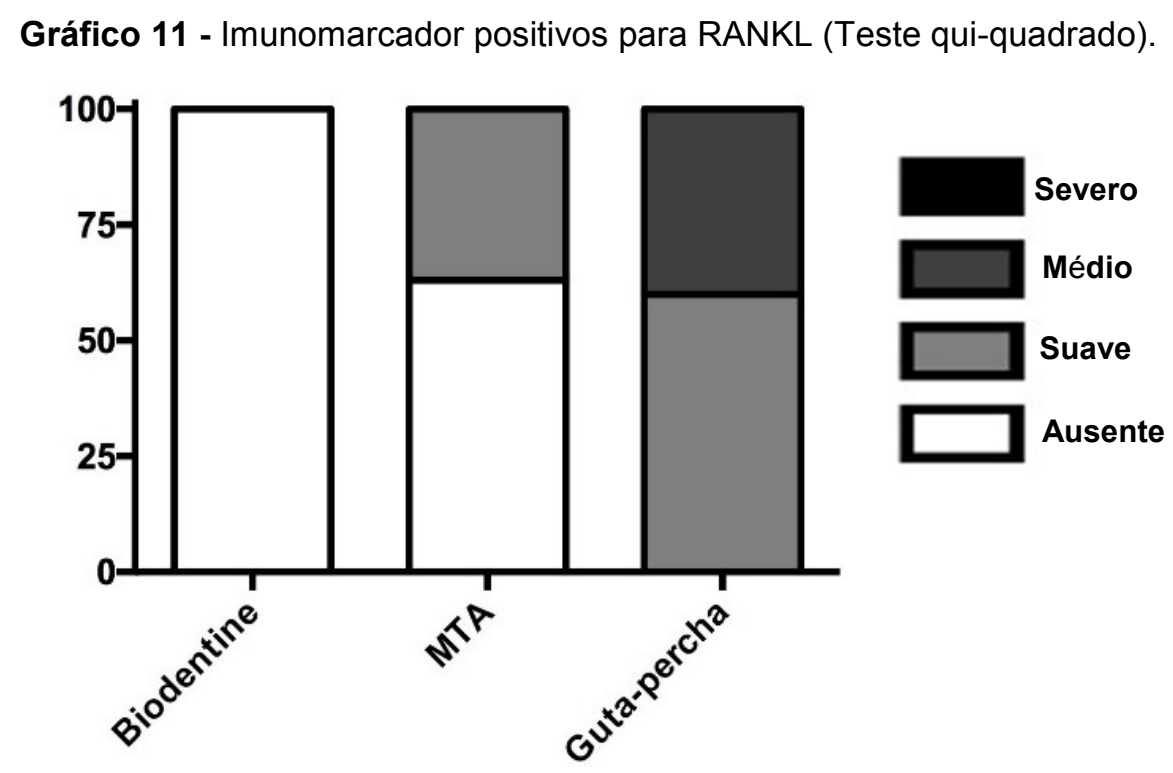

Gráfico 12 - Imunomarcador positivo para OPG (Teste Qui-quadrado).

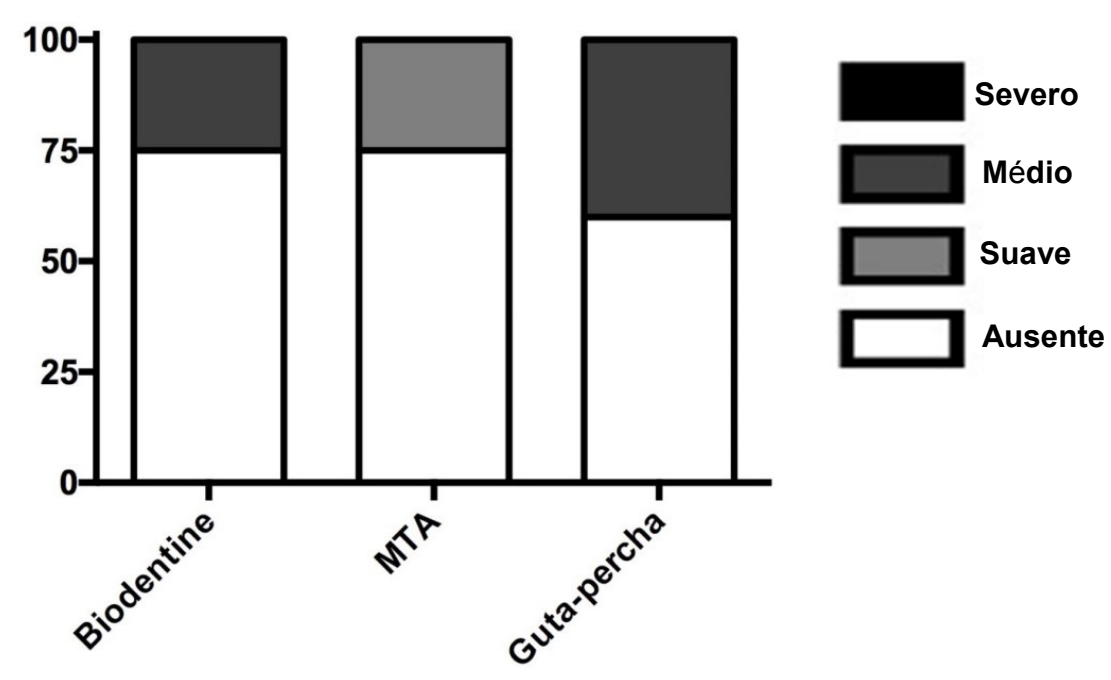



Figura 3 - Fotomicrografias representativas de seç̧ões de imunoistoquímica do marcador RANKL dos grupos tratados com BD (A-B), MTA (C-D) e guta-percha (E-F). A/B: Fotomicrografias num aumento de 10x e 40x, respectivamente, ausência da expressão do marcador que induz a formação de clastos. C/D: Fotomicrografias num aumento de 10x e 20x, respectivamente, com suave presença da expressão do marcador que induz a formação de clastos. E/F: Fotomicrografias num aumento de 10x e 20x, respectivamente, com presença da expressão do marcador que induz a formação de clastos.
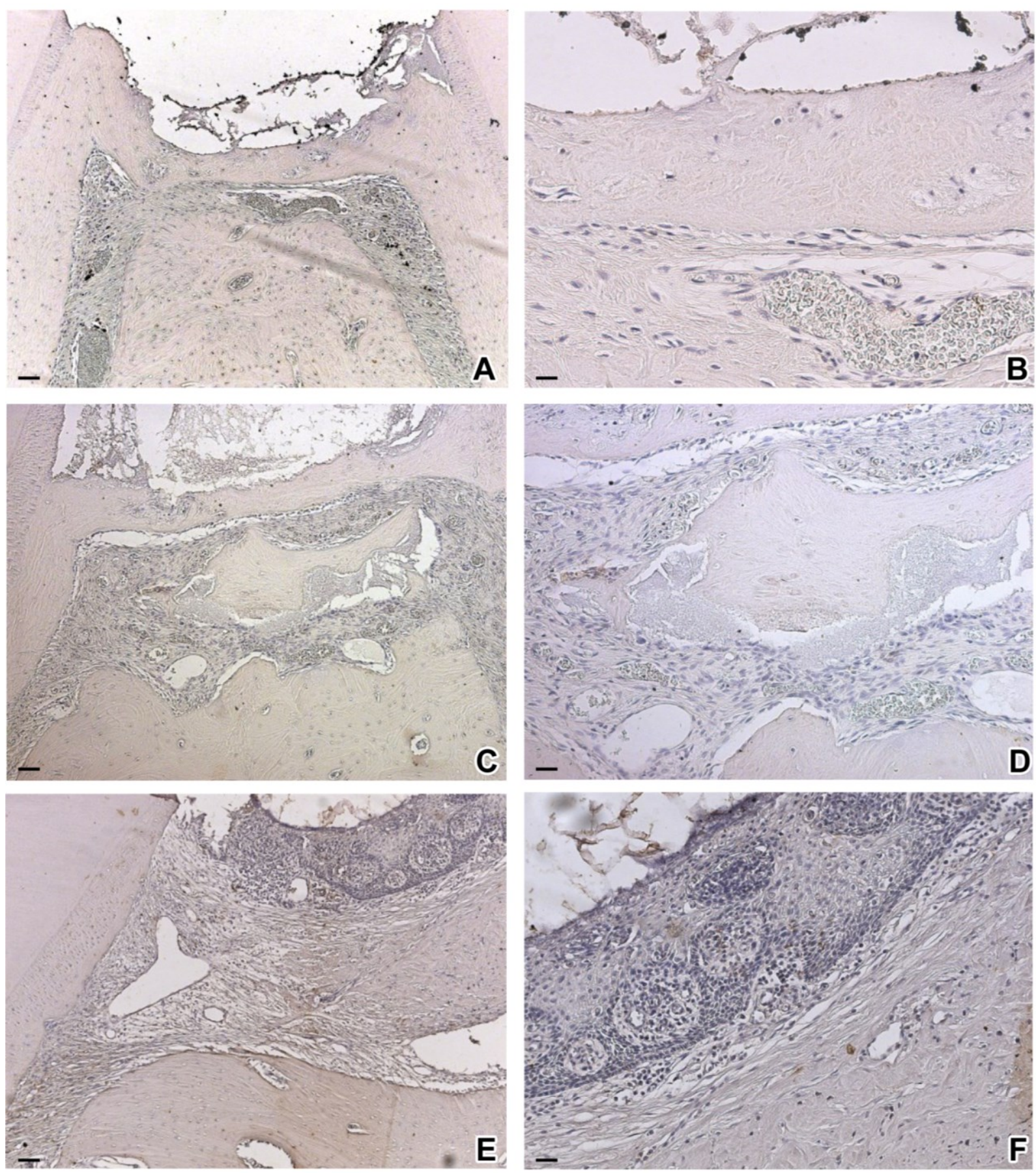

Figura 4 - Fotomicrografias representativas de secções de imunoistoquímica do marcador OPG dos grupos tratados com BD (A-B), MTA (C-D) e guta-percha (E-F). A/B: Fotomicrografias num aumento de 10x e 20x, respectivamente, com presença da expressão do marcador contra a formação de clastos. C/D: Fotomicrografias num aumento de 5x e 10x, respectivamente, presença da expressão do marcador contra a formação de clastos. E/F: Fotomicrografias num aumento de 10x e 40x, respectivamente, com presença da expressão do marcador contra a formação de clastos.
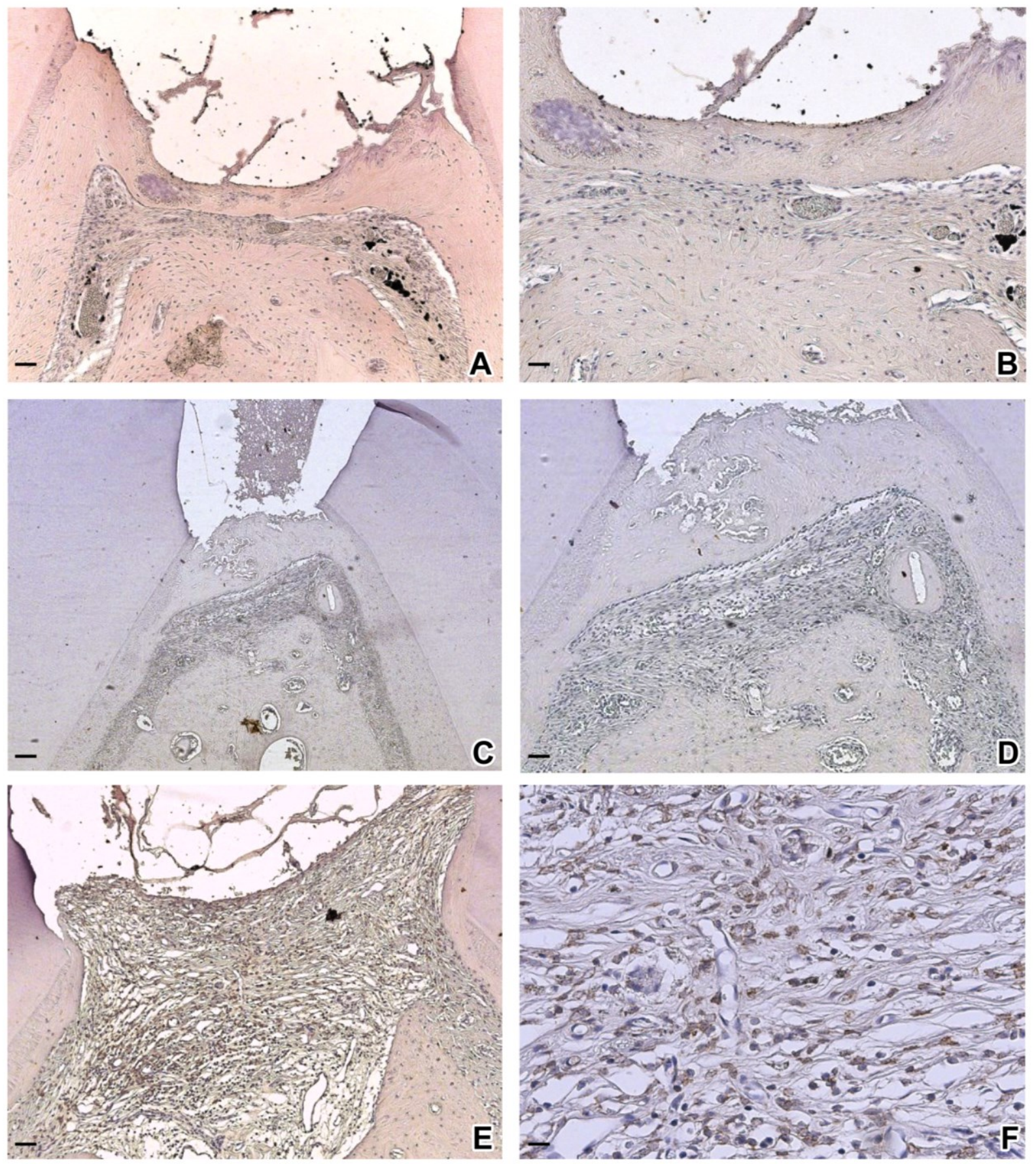



\subsection{Imunofluorescência indireta - Análise das células positivamente marcadas para o fator de transcrição RUNX-2}

A intensidade de imunofluorescência RUNX2 apresentou diferença significativa somente entre a $B D$ e a guta-percha $(P=0,0036)$, sendo mais intensa para a BD. O MTA apresentou intensidade leve, porém com diferença estatisticamente insignificante em relação aos outros grupos ( $P>0,05)$ (Gráfico 13) e (Figura 5).
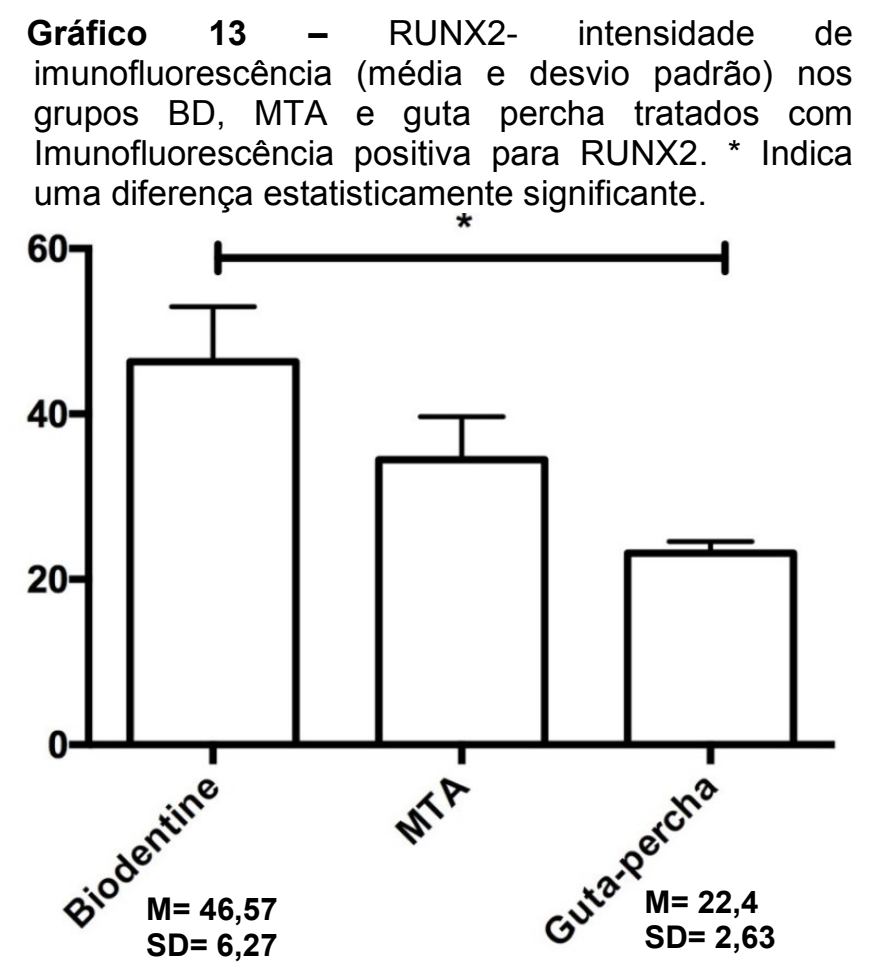

Figura 5 - Fotomicrografias representativas da imunofluorescência indireta. A marcação com RUNX2 mostrou forte intensidade no grupo tratado com BD (A); coloração suave no grupo tratado com MTA (B) e fraca intensidade no grupo tratado com guta-percha (controle positivo) (C) (40x).
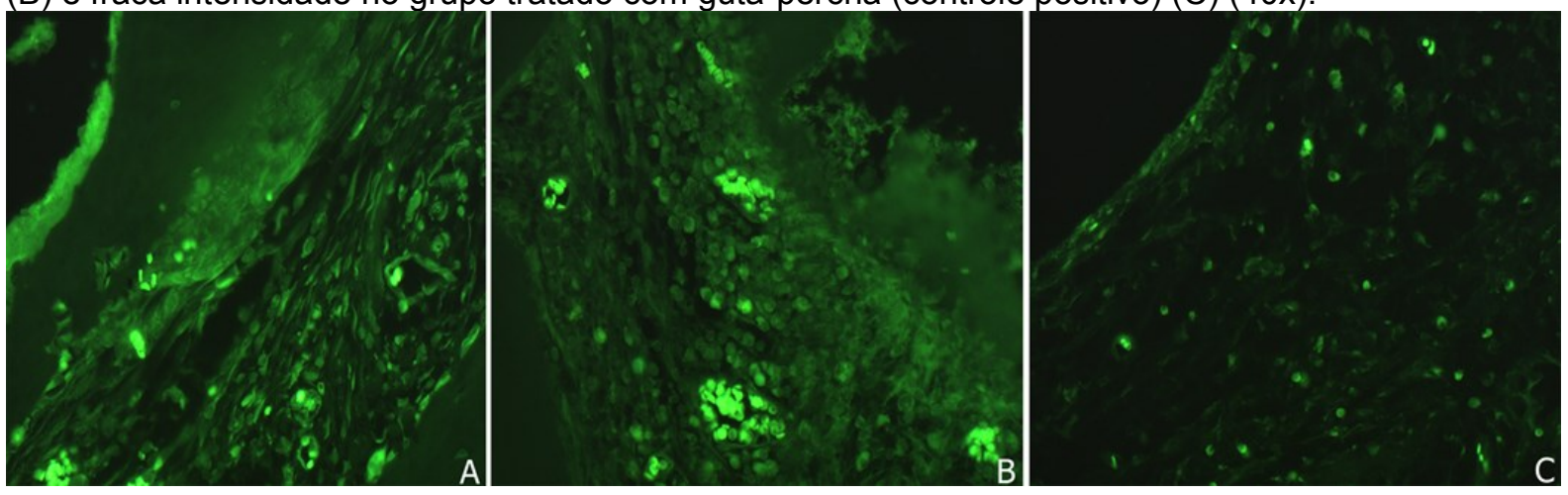

5. Discussão 



\section{DISCUSSÃO}

As perfurações de furca comprometem negativamente o prognóstico do tratamento endodôntico, ocorrendo com maior frequência no assoalho da câmara pulpar (Silva et al., 2009). Após o surgimento do MTA, houve considerável melhora nos prognósticos das patologias endodônticas, alterando o conceito clínico de preservação da estrutura dental (Húngaro Duarte et al., 2009; Silva Neto et al., 2012). A BD surgiu recentemente como um material à base de óxido tricálcico puro, isento das desvantagens do MTA. Entretanto, a literatura é escassa em comparar o MTA e a BD biologicamente para reparação de lesões de furca, por esse motivo, o objetivo deste estudo foi avaliar in vivo, a resposta dos tecidos perirradiculares, após perfuração de furca intencional em dentes de cães.

O modelo experimental canino utilizado no presente estudo procurou simular situações que ocorrem frequentemente em condições clínicas, como por exemplo, microbiota bucal, fluxo salivar e força mastigatória; além disso, os cães são um modelo de estudo há muito validado (ISO 7405:2008) em virtude da semelhança morfológica e biológica no processo de reparo pulpar e periapical com os humanos; podendo resistir a longos períodos de experimentação sob anestesia (Leonardo et al., 1995; Soares, 1996; Nelson-Filho et al., 2002; De Rossi et al., 2005; Queiroz et al., 2005; Noetzel et al., 2006; Tonomaru-Filho et al., 2006; De Rossi et al., 2007; Silva et al., 2008; Silva LA et al., 2009; Silva et al., 2010).

O MTA, por ser considerado padrão ouro nas indicações de pulpotomias segundo a American Academy of Paediatric Dentistry (2012/13), American Association of Endodontists (2013) e vários autores (Soares, 1996; Pitt-Ford et al., 1996; Holland et al., 2001; Nair et al., 2008; Samiee et al., 2010), foi utilizado neste trabalho como grupo controle para comparação com os resultados obtidos com o material avaliado, a BD.

O acompanhamento dos animais submetidos ao procedimento de perfuração de furca intencional foi realizado por um período de 120 dias, com o propósito de restringir esse tempo ao mínimo indispensável para obtenção de resultados conclusivos em atendimento às recomendações do CEUA/FORP-USP e da Lei $n^{\circ}$ 11.794 (Art. 11, §40) e preconizado por diversos autores (Zhu et al., 2003; AlDaafas; Al-Nazhar, 2007; Silva Neto et al., 2010; Silva Neto et al., 2012). 
As imagens radiográficas são amplamente utilizadas como meio diagnóstico na prática clínica odontológica. Inúmeros estudos utilizaram este recurso associado ou não com a avaliação histopatológica das amostras para análise de resultados (Noetzel et al., 2006; Silva MJ et al., 2009; Silva Neto et al., 2010; Vanni et al., 2010; Silva Neto et al., 2012; De Rossi et al., 2014; Simsek et al., 2015). No presente estudo, a análise radiográfica, após 120 dias do experimento, mostrou um melhor desempenho da BD em relação ao MTA em todos os aspectos analisados; muito embora, ambos os materiais apresentassem deposição de tecido mineralizado na área de furca em relação ao controle positivo com guta percha, onde verificamos insucesso na totalidade das amostras avaliadas.

No entanto, os resultados histológicos evidenciaram um melhor desempenho do MTA em relação à BD, quanto à presença de tecido mineralizado depositado, e em relação à área e à espessura desse tecido. Divergências entre os achados radiográficos e histopatológicos já foram relatadas anteriormente, tanto em estudos de terapia pulpar conservadora quanto radical, onde a inflamação crônica pode estar presente apesar da ausência de sintomas clínicos e alterações radiográficas (Barthel; Zimmer; Trope, 2004; De Rossi et al., 2007; Silva LA et al., 2009). As limitações das imagens radiográficas em evidenciar estruturas visíveis no exame histológico são devido à projeção de imagens bidimensionais, além de pequenas distorções geométricas e volumétricas da imagem final pelo exame radiográfico (Rodrigues et al., 2010). Segundo Von Stechow e colaboradores (2003), há uma sobreposição de estruturas anatômicas em uma única imagem, limitando a visualização ou a determinação do tamanho e localização de possíveis lesões, além disso, já está estabelecido pela literatura que a radiografia periapical pode não evidenciar a presença de pontes de tecido mineralizado, principalmente em molares superiores, devido à sobreposição de imagens e de raízes. Neste estudo utilizamos os $2^{\text {os }}$ e $3^{\text {os }}$ pré-molares superiores e os $2^{\text {os }}, 3^{\text {os }}$ e $4^{\text {os }}$ pré-molares inferiores permanentes, e acreditamos que talvez a diferença de resultados radiográficos e histológicos possa ter sido ocasionada também pela dificuldade de visualização do tecido depositado nos dentes superiores.

Comparando os resultados radiográficos e histopatológicos do presente estudo, observamos que a totalidade das amostras seladas com BD não apresentaram reabsorções ósseas; já as amostras seladas com MTA, apresentaram reabsorções ósseas em um quarto das amostras, pela análise radiográfica; 
enquanto, pela análise histopatológica, tanto as amostras seladas com BD quanto as amostras seladas com MTA, se apresentavam isentas de reabsorção.

$\mathrm{Na}$ atualidade, estão disponíveis técnicas de diagnóstico por imagem como a tomografia computadorizada de feixe cônico (TC Cone Beam), especialmente indicada para a região dentomaxilofacial, que permite obter a reprodução de uma secção da região de cabeça e pescoço em qualquer um dos três planos do espaço, fornecendo uma imagem tridimensional do objeto e eliminando a sobreposição de estruturas anatômicas (Garib et al., 2007). Acreditamos que esta poderia ter sido utilizada no presente estudo fornecendo informações imaginológicas mais precisas. Outra vantagem desta técnica consiste na sua alta sensibilidade e especificidade; permitindo a aquisição de imagens tridimensionais com maior qualidade, de forma mais simples, rápida, com menor custo e menor dose de radiação para o paciente, além de dispensar o mecanismo de cortes (Rodrigues et al., 2010); de modo que nas análises qualitativas das imagens, os índices de falso-negativo e falso-positivo são muito baixos. Esta técnica apresenta inúmeras vantagens no diagnóstico por imagens, entretanto, na prática clínica, este método ainda não é um exame rotineiramente utilizado (Garib et al., 2007); além disso, o exame histopatológico ainda é considerado padrão ouro para o diagnóstico das diferentes patologias pulpares e periapicais (De Rossi et al., 2007).

Os resultados da análise histopatológica mostraram que o MTA (controle negativo) apresentou maior frequência de selamento completo, maior espessura e área de tecido mineralizado recém-formado na área de perfuração de furca, que estão de acordo com estudos anteriores (Samie et al., 2010; Zairi et al ., 2012; Unal; Maden; Isidan, 2010; Da Silva et al., 2012). O mecanismo de ação do MTA poderia justificar esses achados, que já estão bem estabelecidos na literatura. O MTA é um cimento bioativo biocompatível e com ação antimicrobiana, capaz de criar um microambiente ideal para reparo (Parirokh; Torabinejad, 2010b). Devido suas propriedades cementogênicas e osteogênicas, é capaz de estimular o crescimento das células do ligamento periodontal, adesão dos osteoblastos e a regeneração óssea (Hakki et al., 2012). Em contato com os tecidos, o MTA estimula as células do sistema imunológico para liberar linfocinas que induzem reparo e regeneração de cemento e marcadores ósseos ativos necessários para biomineralização e reparo de defeitos ósseos periapicais (Economides et al., 2003). Apesar de todos os 
benefícios, o MTA apresenta algumas desvantagens; que incluem potencial de descoloração coronal do dente, presença de alguns elementos tóxicos, tempo de presa longo, difícil manipulação e difícil remoção após sua presa (Camilleri et al., 2005; Song et al., 2006). Ainda assim, no presente estudo, a espessura e a área do tecido mineralizado recém-formado, e a freqüência de perfurações completamente seladas foram significativamente maiores após o uso do MTA; a BD induziu reparo de tecido mineralizado pelo selamento total ou parcial das perfurações de furca em quase todos os casos $(92,9 \%)$, o que mostra uma boa performance biológica deste material. Além disso, ambos os materiais apresentaram 100\% de ausência de reabsorção óssea na região de perfuração de furca. Até o momento, este é o primeiro estudo in vivo a avaliar a resposta de tecidos perirradiculares utilizando a BD para selar perfurações de furca, o que impede uma comparação direta com os resultados de outros trabalhos.

Algumas propriedades e mecanismo de ação da BD poderiam fundamentar nossas descobertas. Devido à sua composição e bioatividade (Cornélio et al., 2017), a BD foi considerada um substituto adequado para o MTA e demonstrou induzir maior deposição de hidroxiapatita (Camilleri; Sorrentino; Damidot, 2013). Estudos também tem demonstrado excelente propriedades físicas e químicas, assim como resistência mecânica (Nielsen et al., 2016), pH elevado e liberação de íons cálcio (Marciano; Duarte; Camilleri, 2016), excelente selamento (El-Khodary et al., 2015), atividade antimicrobiana e baixa solubilidade (Ceci et al., 2016). Do ponto de vista biológico, a ausência de genotoxicidade (Opacié-Galié et al., 2013), baixa citotoxicidade ( Zhou et al., 2013), alta capacidade de manutenção das células da polpa dental em cultura tridimensional (Widbiller et al., 2016) e potencial de mineralização (Daltoé et al. 2016), faz da BD um material ideal para uso clínico. Até o momento, há evidências contraditórias na literatura de acordo com a descoloração dentária causada pela BD. Embora Beatty e Svec, em 2015, relatarem que a BD provocou alteração de cor perceptível em dentes bovinos em comparação com outros cimentos, Marconyak et al. (2016) demonstram que este material apresentou uma menor descoloração em comparação com o ProRoot MTA branco, MTA Angelus e ProRoot MTA.

Segundo Mori et al., em 2014, a BD estimula a atividade dos fibroblastos e a formação de fibras colágenas com insignificante reação inflamatória em tecidos conectivos de ratos. Em contato com a $\mathrm{BD}$, os fibroblastos aderiram à superfície do 
material (Zhou et al., 2013) e as células mesenquimais indiferenciadas exibiram níveis significativamente elevados de genes osteogênicos, com aumento da expressão da fosfatase alcalina, demonstrando a capacidade osteoblastogênica deste material (Lee et al., 2016). Estes achados podem explicar, em parte, a alta capacidade de BD em induzir o reparo da perfuração de furca, com baixa presença de infiltrado inflamatório nessa região.

No presente estudo, as amostras seladas com MTA e BD apresentaram menos células inflamatórias do que o grupo controle positivo (guta percha), além disso, houve diferença significante somente para as amostras do grupo da BD. Um estudo in vivo recente em tecido subcutâneo de ratos, mostrou que o número de células inflamatórias e as células imunomarcadas com interleucina- 6 foram significativamente maiores após 7 e 15 dias de exposição nas amostras com BD em comparação com as amostras com MTA. Entretanto, após 60 dias houve uma redução significante da reação inflamatória, e ambos os materiais mostraram cápsulas com numerosos fibroblastos e feixes de fibras colágenas (da Fonseca et al., 2016); corroborando com nossos achados. Estes resultados podem explicar algumas amostras com infiltração de células inflamatórias após o selamento das perfurações de furca com MTA ou BD. Além disso, está bem estabelecido que as células inflamatórias participam do reparo do tecido mineralizado e atuam na ativação de outras células que são essenciais para a formação, reparação e remodelação óssea (Loi et al., 2016).

A descoberta do sistema (RANK / RANKL / (OPG) no final dos anos 1990 foi um avanço na elucidação dos mecanismos reguladores subjacentes à osteoclastogênese e reabsorção óssea (Greenfield; Bi; Miyauchi, 1999; Lacey et al., 1998). A expressão RANKL/OPG foi primeiramente detectada em odontoblastos, ameloblastos, células da polpa e ligamento periodontal. A ligação de RANKL ao seu receptor, RANK, resulta na fusão, diferenciação, ativação e sobrevivência de osteoclastos (Lacey et al., 1998). A OPG funciona como um receptor para RANKL, que o impede de vincular-se ao RANK. A OPG é, portanto, considerado um fator protetor contra a perda óssea (Simonet et al., 1997). O desequilíbrio desse sistema é crucial na etiologia de desordens ósseas, uma vez que a intensa atividade de reabsorção leva à perda óssea (Rodan; Martin, 2000; Romas et al., 2002). No presente estudo, o RANKL esteve discretamente presente somente nas amostras 
seladas com MTA, quando comparadas às amostras seladas com guta percha (controle positivo), onde $100 \%$ das suas amostras houve a presença do RANKL. Lara et al. (2015), realizaram um estudo para avaliar o padrão de resposta imune que ocorre em tecido periodontal na área de perfuração de furca em dentes de camundongos selados com MTA e parafina (controle positivo) após 7, 14 e 21 dias, por meio da expressão do gene das citocinas inflamatórias e RANKL. Após 21 dias, ainda observou-se níveis de mRNA de RANKL, e citocinas inflamatórias em níveis reduzidos, após o selamentos com MTA. Em nosso estudo, o RANKL ainda estava presente em algumas amostras seladas com MTA após 120 dias; sem entretanto, comprometer os resultados finais e satisfatórios do MTA. Por outro lado, quanto à análise em relação ao marcador contra a formação de osteoclastos, a OPG, foi verificada sua presença em aproximadamente $25 \%$ das áreas de furca das amostras seladas tanto com MTA, quanto com a BD. Estudos mostraram que células do ligamento periodontal de camundongos expressaram mRNA de OPG (Sakata et al., 1999) e produziram a proteína OPG in vitro (Wada et al., 2001). A OPG secretada apresentou uma capacidade de inibir a diferenciação dos osteoclastos em cultura de medula óssea de camundongos (Wada et al., 2001). Diante dos resultados obtidos relacionados à presença da OPG, deposição de tecido mineralizado e ausência de reabsorção óssea nas amostras seladas tanto com MTA quanto com BD, estes estudos podem sugerir que as células dos tecidos perirradiculares impeçam a reabsorção óssea por meio do mecanismo dependente de OPG.

RUNX-2 é um marcador de mineralização e um fator de transcrição para a diferenciação dos odontoblastos. Estudo de Komori et al. (1997) demonstrou que o fator RUNX-2 é essencial para a formação de tecido ósseo normal. Os reparos nas áreas de furca deste trabalho também se confirmaram pelo ensaio de imunofluorescência indireta e foram observadas células marcadas positivamente para o RUNX-2 no ligamento periodontal, assim como também no tecido mineralizado neoformado adjacente, tanto nas amostras seladas com BD quanto nas amostras seladas com MTA, e sua ausência nas amostras de guta percha (controle positivo); sendo que houve diferença estatisticamente significante somente entre a BD e a guta percha. Um estudo recente de cultura de células (Widbiller et al., 2016) mostrou a expressão de RUNX2 em células diferenciadas da polpa em ambos os grupos MTA e BD, em todos os períodos de avaliação. Sabe-se que durante o desenvolvimento ósseo, o RUNX2 induz a diferenciação osteoblástica, aumenta a 
expressão de vários genes de proteínas da matriz óssea e aumenta o número de osteoblastos imaturos (Komori, 2010). Portanto, embora não seja conhecida a natureza exata do tecido mineralizado em resposta a BD, a expressão de RUNX2 no presente estudo confirma o papel de biomineralização e a capacidade de indução de reparo deste material quando usado para selar perfurações de furca.

Em contato com o tecido perirradicular neste estudo, a BD induziu o reparo da perfuração de furca devido à criação de um microambiente minerarizante com leve resposta inflamatória. Pode-se supor que se um período de avaliação mais longo fosse usado, este material poderia apresentar frequência e espessura de tecido mineralizado completamente formado comparável ao MTA. 

6. Conclusões 



\section{CONCLUSÕES}

Sob as condições deste estudo in vivo, pode-se concluir que tanto a BD como o MTA proporcionaram bons resultados histopatológicos e ambos podem ser considerados como material adequado de reparo de perfuração de furca. Entretanto, o MTA induziu a formação de tecido mineralizado com maior espessura e área e apresentou maior frequência de selamento completo das perfurações de furca; além disso, o RUNX2 parece ser um importante fator de transcrição osteogênica para a mineralização de ambos os materiais. 

REFERÊNCIAS 



\section{REFERÊNCIAS}

Albuquerque DS, Gominho LF, Santos RA. Histologic of pulpotomy performed with ethyl-cyanoacrylate and calcium hydroxide Braz Oral Res. 2006;20(3):226-30.

Al-Daafas A, Al-Nazhan S. Histological evaluation of contaminated furcal perforation in dogs' teeth repaired by MTA with or without internal matrix. Oral Surg Oral Med Oral Pathol Oral Radiol Endod. 2007;103:e92-9.

Abedi HR, et al. The use of mineral trioxide aggregate cement (MTA) as a direct pulp capping agent. J Endod. 1996;22:199.

Aggarwal V, et al. Comparative evaluation of push-out bond strength of ProRoot MTA, Biodentine, and MTA Plus in furcation perforation repair. J Conserv Dent. 2013;16:462-5.

Aqrabawi J. Sealing ability of amalgam, super-EBA cement, and MTA when used as retrograde filling materials.Br Dent J. 2000;188:266-8.

Alhadainy HA, Himel VT. Evaluation of the sealing ability of amalgam, Cavit and glass ionomer cement in the repair of furcation perforations. Oral Surg Oral Med Oral Pathol. 1993;75:362-6.

Alhadainy $\mathrm{H}$. Root perforations: A review of literature. Oral Surg Oral Med oral Pathol. 1994:78:368-74.

Asgary S, et al. A comparative study of histologic response to different pulp capping materials and a novel endodontic cement. Oral Surg Oral Med Oral Pathol Oral Radiol Endod. 2008;106(4):609-14.

Azim AA, Lloyd A, Huang GT-J. Management of longstanding furcation perforation using a novel approach. JOE. 2014; 40:8:1255-59.

Bargholz C. Perforation repair with mineral trioxide aggregate: a modified matrix concept. Int Endod J. 2005;38:59-69.

Barthel CR, Zimmer S, Trope M. Relationship of radiologic and histologic signs of inflammation in human root-filled teeth. J Endod. 2004 Feb;30(2):75-9.

Bates CF, Carnes DL, del Rio CE. Longitudinal sealing ability of mineral trioxide aggregate as a root-end filling material. J Endod. 1996;22:575-8.

Beatty $\mathrm{H}$, Svec T. Quantifying coronal tooth discolorztion caused by Biodentine and Endosequence root repair material. J Endod 2015;41:2036-9.

Beertsen W, van den Bos T. Alkaline phosphatase induces the mineralization of sheets of collagen implanted subcutaneously in the rat. J Clin Invest 1992; 89:19741980.

Benenati FW, et al. Recall evaluation of iatrogenic root perforations repaired with amalgam and gutta percha. J Endod 1986;12:161-6. 
Bernabé PFE, et al. Healing process of root end treatment using ultrasonic instrument and MTA or Portland cement. Int Endod J. 2002;55:65-9.

Bidar $\mathrm{M}$, et al. Osteoblastic cytokine response to gray and white mineral trioxide aggregate. Iran Endod J. 2011;6(3):111-5.

Biodentine Scientific File. Active Biosilicate Technology ${ }^{\mathrm{TM}}$, 2010, Septodont. SaintMaur-des-fossés Cedex, France: R\&D Department. www.septodont.fr.

Bogaerts P. Treatment of root perforations with calcium hydroxide and Super EBA cement: a clinical report. Int Endod J 1997 May;30:210-9.

Bogen G, Kim JS, Bakland LK. Direct pulp capping with mineral trioxide aggregate: an observacional study. J Am Dent Assoc. 2008;139(3):305-15; quiz 305-15. in J Am Dent Assoc.139(5):541.

Broon $\mathrm{JN}$, et al. Healing of root perforations treated with mineral trioxide aggregate (MTA) and Portland cement. J Appl Oral Sci. 2006;14:305-11.

Camargo $\mathrm{CH}$, et al. Topographical, diametral, and quantitative analysis of dentin tubules in the root canals of human and bovine teeth. J Endod 2007;33:4226.

Camilleri J, et al. Biocompatibility of two commercial forms of mineral trioxide aggregate. International Endodontic Journal. 2004:37:699-04.

Camilleri J, et al. The constitution of mineral trioxide aggregate. Dent Mater 2005; 21:297-303.

Camilleri J, Ford TRP. Review, Mineral trioxide aggregate: a review of the constituents and biological properties of the material. Int. Endo J.2006;39:747-54.

Camilleri $\mathrm{J}$, et al. The constitution off mineral trioxide aggregate. Dent Mater 2005;21:297-03.

Camilleri J, et al. Characterization and analyses of acid extractable and leached trace elements in dental cements. International Endodontic Journal 2012;5(8):737-43.

Camilleri J, Sorrentino F, Damidot D. Investigation of the hydration and bioactivity of radiopacified tricalcium silicate cement, Biodentine and MTA Angelus. Dent Mater. 2013b;29(5):580-93.

Cau JYM, et al. An in vitro study of furcation perforation repair using calcium phosphate cement. J Endod 1997;23:588-93.

Chang HK, et al. Properties of a new root-end filling material. J Endod 2005 31:665668.

Chang SW. Chemical characteristics of mineral trioxide aggregate and its hydration reaction. Restor Dent Endod. 2012;37:188-193.

Ceci $\mathrm{M}$, et al. Biological and chemical physical properties of root- end filling materials: a comparative study. J Consev Dent 2015;18:94-9. 
Coomaraswamy KS, Lumley PJ, Hofman MP. Effect of bismuth oxide radiopaciffer content on the material properties of an endodontic Portland cement-based (MTAlike) system. Journal of endodontics. 2007:33: 295-8.

Coon D, et al. The role of cyclooxygenase-2 (COX-2) in inflammatory bone resorption. J Endod 2007;33:432-6.

Cornélio AR, et al.Bioactivity of MTA Plus, Biodentine and experimental calcium silicate-based cements in human osteoblast-like cells. Int EndodJ 2017;50;39-47.

Cui $\mathrm{J}$, et al. Arsenic levels and speciation from ingestion exposures to biomarkers in Shanxi, China: implications for human health. Environ Sci Technol. 2013;21;47(10):5419-24.

da Fonseca TS, et al. In vivo evaluation of the inflammatory response and IL-6 immunoexpression promoted by Biodentine and MTA Angelus. Int Endod J. 2016;49:145-53.

Daltoé $\mathrm{MO}$, et al. Expression of mineralization markers during pulp response to Biodentine and Mineral Trioxide Aggregate. JOE. 2016:42:4:596-03.

Dammaschke $\mathrm{T}$, et al. Chemical and physical surface and bulk material characterization of white ProRoot MTA and two Portland cements. Dent Mater. 2005;21:731-8.

da Silva EJ et al. Furcal-perforation repair with mineral trioxide aggregate: two years follow up. Indian J Dent Res 2012;23:542-5.

De-Deus G, et al. MTA versus Portland cement as repair material for furcal perforations: a laboratory study using a polymicrobial leakage model. International Endodontic Journal. 2006:39: 293-298.

De-Deus G, et al. Cytotoxicity of MTA and Portland cement on human ECV 304 endothelial cells. International Endodontic Journal. 2005 38, 604-9.

De Rossi A, Silva LA, Leonardo MR, Rocha LB, Rossi MA. Effect of rotary or manual instrumentation, with or without a calcium hydroxide $/ 1 \%$ chlorhexidine intracanal dressing, on the healing of experimentally induced chronic periapical lesions. Oral Surg Oral Med Oral Pathol Oral Radiol Endod. 2005;99:628-36.

De Rossi A, et al. Morphometric analysis of experimentally induced periapical lesions: radiographic vs histopathological findings. Dentomaxillofac Radiol. 2007a;36(4):211-7.

De Rossi A, Rocha LB, Rossi MA. Application of fluorescence microscopy on hematoxylin and eosin-stained sections of healthy and diseased teeth and supporting structures. J Oral Pathol Med. 2007b;36(6):377-81.

De Rossi A, et al. Comparison of pulpal responses to pulpotomy and pulp capping with Biodentine and Mineral Trioxide Aggregate in dogs. Journal of Endodontics. 2014:40:1362-9. 
Do Nascimento $\mathrm{C}$, et al. Bone repair using mineral trioxide aggregate combined to a material carrier, associated or not with calcium hydroxide in bone defects. Micron. 2008 Oct;39(7):868-74.

Economides $\mathrm{N}$, et al. Short-term perirradicular tissue response to mineral trioxde aggregate (MTA) as root-end filling material. Int Endod J 2003;36:44-8.

El Deeb ME, et al. An evaluation of the use of amalgam, Cavit and calcium hydroxide in the repair of furcation perforations. J Endodon 1982;8:459-66.

El-Khodary et al. Sealing ability of four calcium containing cements used for repairing furcal perforations: in primary molars: an in vitro study. J Contemp Dent Pract 2015: 16:733-9.

El Tawil SB, El Dokkyl NA, El Hamid DA. Sealing ability of MTA versus Portland cement in the repair of furcal perforations of primary molars: A dye extraction leakage model. J Am Sci. 2011;7:1037-43.

Eppala J, et al. Evaluation of sealing ability of MM-MTA, Endosequence, and Biodentine as furcation repair materials: UV spectrophotometric analysis. $\mathrm{J}$ of Conservative Dentistry. 2014:vol. 17, 340-43.

Estrela C, et al. Antimicrobial and chemical study of MTA, Portland cement, calcium hydroxide paste, Sealapex and Dycal. Braz Dent J. 2000;11:3-9.

Farzan SF, Korrick S, Li Z, Enelow R, Gandolfi AJ, Madan J, Nadeau K, Karagas MR. In utero arsenic exposure and infant infection in a United States cohort: A prospective study. Environ Res. 2013;13.

Favieri $\mathrm{A}$, et al. Use of biomaterials in periradicular surgery: a case report. J Endod 2008;34:490-4.

Ferracane JL, Cooper PR, Smith AJ. Can interaction of materials with the dentin pulp complex contribute to dentin regeneration? Odontology. 2010;98(1):2-14.

Ferris DM, Baumgartner JC. Perforation repair comparing two type of mineral trioxide aggregate. J Endod. 2004;30:422-24.

Ford TR, et al. Use of mineral trioxide aggregate for repair of furcal perforations. Oral Surg Oral Med Oral Pathol Oral Radiol Endod. 1995;79(6):756-63.

Freeman E. Periodontium. In: Ten Cate AF, ed. Oral histology: development, structure, and junction. St. Louis: Mosby, 1994: 276-312.

Garib et al. Tomografia computadorizada de feixe cônico (Cone beam): entendendo este novo método de diagnóstico por imagem com promissora aplicabilidade na Ortodontia. R Dental Press Ortodon Ortop Facial 2007:12(2), 139-56.

Gomes-Cornélio AL, et al. Cytotoxicity and genotoxicity of calcium silicate-based cements on na osteoblast lineage. Braz Oral Res. 2016; 30(1):e48. 
Gorduysus M, et al. Cytotoxic effects of four different endodontic materials in human periodontal ligament fibroblasts. J Endod 2007;33:1450-4.

Grazziotin-Soares R, et.al. Effect of bismuth oxide on White mineral trioxide aggregate: Chemical characterization and physical properties. International Endodontic Journal 2014;47, 520-33.

Greenfield EM, Bi Y and Miyauchi A: Regulation of osteoclast activity. Life Sci 65: 1087-1102, 1999.

Groeneveld MC, Everts V, Beertsen W. Alkaline phosphatase activity in the periodontal ligament and gingiva of the rat molar: its relation to cementum formation. J Dent Res 1995;74:1374-1381.

Guia Terapêutico de Bretas, $2^{a}$ edição, 2007.

Hakki SS, et al. Effects of mineral trioxide aggregate on cell survival, gene expression associated with mineralized tissues, and biomineralization of cementoblasts. J Endod 2009;35:513-9.

Hakki SS, et al. Periodontal ligament fibroblasts response to root perforations restored with different materials: a laboratory study. Int End J 2012:45;240-8.

Hamad HA, Tordik PA, McClanaban SB. Furcation perforation repair comparing gray and white MTA: a dye extraction study. J Endod.2006;32:337-40.

Hashem AAR, Hassanien EE. Pro Root MTA, MTA-Angelus and IRM used to repair large furcation perforations: sealability study. J Endod.2008;34:59-61.

Hasheminia SM, et al. A comparative study of three treatment methods of direct pulp capping in canine teeth of cats: a histologic evaluation. Lasers Med Sci Lasers Med Sci. 2010 Jan;25(1):9-15.

Holland $\mathrm{R}$, et al. Mineral trioxide aggregate repair of lateral root perforations. J Endod. 2001;27:281-4.

Húngaro Duarte MA, et al. Radiopacity of Portland cement associated with diferente radiopacifiyng agents. J Endod..2009;35(5):737-40.

Ibricevic $\mathrm{H}$, Al-Jame Q. Ferric sulphate and formocresol in pulpotomy of primary molars: long term follow-up study. Eur J Paediatr Dent. 2003;4(1):28-32.

International Organization for Standardization. ISO 7405:2008: Evaluation of biocompatibility of medical devices used in dentistry. Geneva: ISO; 2008.

Jew RCK, et al. A histologic evaluation of periodontal tissues adjacent to root perforations filled with Cavit. Oral Surg Oral Med Oral Pathol 1982;54:124-35.

Katge FA, et al. Sealing ability of mineral trioxide aggregate Plus ${ }^{\mathrm{TM}}$ and Biodentine $\mathrm{T}^{\mathrm{TM}}$ for repair of furcation perforation in primary molars: An in vitro study. Contemp Clin Dent. 2016 oct-dec;7(4):487-492. 
Keiser K, Johnson CC, Tipton DA. Citotoxicity of mineral trioxide aggregate using human periodontal ligament fibroblasts. J Endod. 2000;26:288-91.

Kenchappa $M$, et al. Dentine in capsule: Clinical case reports. Journal of Indian Society of Pedodontics and preventive. 2015, v:33:250-254.

Kettering JD, Torabinejad M. Investigation of mutagenicity of mineral trioxide aggregate and other commonly used root-end filling materials. $J$ Endod. 1995;21:537-9.

Koh ET, et al. Mineral trioxide aggregate stimulates a biological response in human osteoblasts. J Biomed Mat Res. 1997;37:432-9.

Koh ET, et al. Celular response to mineral trioxide aggregate. J Endod. 1998;24:5437.

Komori $\mathrm{T}$, et al. Targeteddisruption of Cbfa1 results in a complete lack of bone formation owing to maturational arrest of osteoblasts. Cell, 1997:89(5):755-64.

Komori T. Regulation of bone development and extracellular matrix protein genes by RUNX-2. Cell Tissue Res. 2010:339:198-95.

Koubi G, Colon P, Franquin JC, Hartmann A, Richard G, Faure MO, Lambert G. Clinical evaluation of the performance and safety of a new dentine substitute, Biodentine, in the restoration of posterior teeth - a prospective study. Clin Oral Investig. 2013;17(1):243-9.

Kuratate $M$, et al. Immunohistochemical analysis of nestin, osteopontin, and proliferating cells in the reparative process of exposed dental pulp capped with mineral trioxide aggregate. J Endod 2008;34:970-4.

Lacey D, et al. Osteoprotegerin ligand is a cytokine that regulates osteoclast differentiation and activation. Cell. 1998; 93:165-176.

Laurent $\mathrm{P}$, Camps J, About I. Biodentine $\left({ }^{\mathrm{TM}}\right)$ induces TGF- $\beta 1$ release from human pulp cells and early dental pulp mineralization. Int Endod J. 2012;45(5):439-48.

Laurent $\mathrm{P}$, et al. Induction of specific cell responses to a $\mathrm{Ca}(3) \mathrm{SiO}(5)$-based posterior restorative material. Dent Mater. 2008;24(11):1486-94.

Lee BN, et al. Effects of 3 endodontic bioactive cements on osteogenic differentiation in mesenchymal stem cells. J Endod 2014;40:1217-22.

Lee SJ, Monsef M, Torabinejad M. Sealing ability of a mineral trioxide aggregate for repair of lateral root perforations. J Endod. 1993;19:541-4.

Leiendecker AP, et al. Effects of calcium silicate-based materials on collagen matrix integrity of mineralized dentin. J Endod. 2012;38:829-33.

Leonardo MR, et al. Effect of a calcium hydroxide-based root canal dressing on periapical repair in dogs: a histological study. Oral Surg Oral Med Oral Pathol Oral Radiol Endod. 2006 Nov;102(5):680-5. 
Leonardo MR, et al. Histopathological observations of periapical repair in teeth with radiolucent areas submitted to two different methods of root canal treatment. J Endod. 1995;21(3):137-41.

Liapatas S, Nakou M, Rontogianni D. Inflammatory infiltrate of chronic periradicular lesions: an immunohistochemical study. Int Endod J 2003;36(7):464-71.

Loi F, et al. Inflamation, fracture and bone repair. Bone 2016;86:119-30.

Ma J, et al. Biocompatibility of Two Novel Root Repair Materials. J Endod. 2011;37:793-8.

Main C, et al. Repair of root perforations using mineral trioxide aggregate: A longterm study. J Endod.2004;30:80-3.

Makkawy HA, et al. Cytotoxicity of root perforation repair materials. J Endod. 1998 Jul;24(7):477-9.

Malkoundu O, Kazandag MK, Kazazoglu E. A review on Biodentine, contemporary dentine replacement and repair Material. BioMed Research International, 2014.

Marciano MA, Duarte MA, Camilleri J. Calcium silicate-based sealers: assessment of psyicochemical properties, porosity and hydration. Dent Mater 2016;32:e30-40.

Marconyak LJ Jr, et al. A comparison of conora tooth discoloration elicited by various endodontic reparative materials. J Endod 206:42:470-3.

Meister F Jr, et al. Endodontic perforations which resulted in alveolar bone loss. Report of five cases. Oral Surg Oral Med Oral Pathol Oral Radiol Endod 1979;47:463-70.

Mente J, et al. Treatment outcome of mineral trioxide aggregate: repair of root perforations. J Endod 2010 36:208-231.

Mesquita Jr D, et al. Aspectos celulares e moleculares da inflamação. RBM Revista Brasileira de Medicina, 2008: 66-88.

Moghaddame-Jafari S, et al. Effect of ProRoot MTA on pulp cell apoptosis and proliferation in vitro. J Endod. 2005;31(5):387-91.

Moore J, Fitz-Walter P, Parashos P. A micro-computed tomographic evaluation of apical root canal preparation using three instrumentation techiniques. Int Endod J. 2009;42:1057-64.

Morandi R. Avaliação histomorfológica realizada em dentes de cães com lesão periapical, após apicectomia e obturação retrógada convencional com cimentos à base de óxide de zinco e eugenol e o agregado de trióxido mineral. Araçatuba, 1999. 319p. Dissertação (Mestrado em Endodontia) - Faculdade de Odontologia, Universidade Estadual Paulista. 
Moretton TR, et al. Tissue reactions after subcutaneous and intraosseous implantation of mineral trioxide aggregate and ethoxybenzoic acid cement. J Biomed Mater Res. 2000;52(3):528-33.

Mori GG, et al. Biocompatibility evaluation of Biodentine in subcutaneous tissue of rats. J Endod 2014;40:1485-8.

Nair PNR, et al. Histological, ultrastructural and quantitative investigations on the response of healthy human pulps to experimental capping with mineral trioxide aggregate: a randomized controlled trial. Int Endod J. 2008;41(2):128-50.

Nakata TT, Bae KC, Baumgarther JC. Perforation repair comparing mineral trioxide aggregate and amalgam using an anaerobic bacterial leakage model. $\mathrm{J}$ Endod. 1998;24:184-6.

Nelson-Filho P, Leonardo MR, Silva LA, Assed S. Radiographic evaluation of the effect of endotoxin (LPS) plus calcium hydroxide on apical and periapical tissues of dogs. J Endod. 2002;28(10):694-6.

Niederman R, Westernoff $\mathrm{T}$, Lee $\mathrm{C}$, et al. Infection-mediated early-onset periodontal disease in P/E-selectin-deficient mice. J Clin Periodontol 2001;28(6):569-75.

Nielsen MJ, et al. Mechanical properties of new dental pulp-capping materials. Gen Dent 2016;64:44-8.

Nishtha $\mathrm{P}$, et al. Comparing gray and white mineral trioxide aggregate as a repair material for furcation perforation: An in vitro dye extraction study. J of Clin and Diagnostic Research. 2014 oct, 8(10):ZC70-ZC73.

Noetzel J, et al. Tissue responses to an experimental calcium phosphate cement and mineral trioxide aggregate as materials for furcation perforation repair: a histological study in dogs. Clin Oral Invest. 2006;10:77-83.

Nowicka A, et al. Response of human dental pulp capped with biodentine and mineral trioxide aggregate. J Endod. 2013;39(6):743-7.

Opacic-Galic V, Petrovic V, Zivkovic S, Jokanovic V, Nikoli B, Kneževic-Vukcevic J, Mitic-culafic D. New nanostructural biomaterials based on active silicate systems and hydroxyapatite: characterization and genotoxicity in human peripheral blood lymphocytes. Int Endod J. 2013;46(6):506-16.

Paranjpe $\mathrm{A}$, Zhang $\mathrm{H}$, Johnson JD. Effects of mineral trioxide aggregate on human dental pulp cells after pulp-capping procedures. J Endod. 2010;36(6):1042-7.

Parikrokh M, Torabinejad M. Mineral Trioxide Aggregate: A comprehensive literature review: Chemical, physical and antibacterial properties. J Endod 2010a;36:16-27.

Parirokh M, Torabinejad M. Mineral trioxide aggregate: A comprehensive literature review: Clinical applications, drawbacks, and mechanism of action. J Endod. 2010b;36:400-13. 
Pérard M, et al. Spheroid model study comparing the biocompatibility of Biodentine and MTA. J Mater Sci Mater Med. 2013;24(6):1527-34.

Pelliccioni GA, et al. Evaluation of osteoblast-like cell response to Proroot MTA (mineral trioxide aggregate) cement. J Mater Sci Mater Med. 2004:15(2):167-73.

Perinpanayagam H, Al-Rabeah E. Osteoblasts interact with MTA surfaces and express Runx2. Oral Surg Oral Med Oral Pathol Oral Radiol Endod 2009;107:590-6.

Pitt-Ford TR, Torabinejad M, Abedi HR, Bakland LK, Kariya- wasam SP. Using mineral trioxide aggregate as a pulp-capping material. $J$ Am Dent Assoc. 1996;127:1491-4.

Queiroz AM, Assed S, Leonardo MR, Nelson-Filho P, Silva LA. MTA and calcium hydroxide for pulp capping. J Appl Oral Sci. 2005;13(2):126-30.

Rajasekharan S, Martens LC. Biodentine ${ }^{\mathrm{TM}}$ material characteristics and clinical applications: a review of the literature. Eur Arch Paediatr Dent 2014, 15:147-158.

Reston EG, de Souza Costa CA. Scanning electron microscopy evaluation of the hard tissue barrier after pulp capping with calcium hydroxide, mineral trioxide aggregate (MTA) or ProRoot MTA. Aust Endod J 2009;35(2):78-84.

Roberts HW, et al. Mineral trioxide aggregate material use in endodontic treatment: a review of the literature. Dent Mater 2008;24:149-64.

Rodrigues MGS, et al. Tomografia computadorizada por feixes cônico: formação de imagem, indicações ecritérios para prescrição.Odontol.Clin-Cient (online)2010;9:2abr/jun;115-18.

Ruddle JC. Noncirurgical endodontic retreatment. In:CohenS, Burns RC, eds. Pathways of the pulp, $8^{\text {th }}$ ed. St. Louis: Mosby Inc, 2002;919.

Salako $\mathrm{N}$, et al. Comparison of bioactive glass, mineral trioxide aggregate, ferric sulfate, and formocresol as pulpotomy agents in rat molar. Dent Traumatol 2003;19:314-20.

Sakata M, et al. Expression of osteoprotegerin (osteoclastogenesis inhibitory factor) in cultures of human dental mesenchymal cells and epithelial cells. J Bone Miner Res 1999; 14:1486-1492.

Sanghavi T, Shah N, Shah RR. Comparative analysis of sealing ability of biodentine and calcium phosphate cement against mineral trioxide aggregate as a furcal perforation repair material: An in vitro study. National Journal of Integrated Research in Medicine. 2013;4:56-60.

Schembri M, Peplow G, Camilleri J. Analyses of heavy metals in mineral trioxide aggregate and Portland cement. J Endod. 2010;36(7):1210-5.

Schmitz JP, Hollinger JO, Milam SB. Reconstruction of bone using calcium phosphate bone cements: a critical review. J Oral Maxillofac Surg 1999, 57:11221226. 
Schwartz RS, et al. Mineral trioxide aggregate: a new material for endodontics. J. Am. Dent. Assoc. 1999;30:967-75.

Seltzer S, et al. Endodontic failures--an analysis based on clinical, roentgenographic, and histologic findings. II. Oral Surg Oral Med Oral Pathol. 1967 Apr;23(4):517-30.

Seltzer S, Sinai I, August D. Periodontal effects of root perforations before and during endodontic procedures. J Dent Res 1970;49:332-9.

Septodont. Biodentine - Active Biosilicate Technology, scientific file.Saint-Maur-desFossés Cedex, France: R\&D Department, Septodont; 2010.

Shayegan A, et al. Biodentine used as a pulp-capping agent in primary pig teeth. Pediatryc Dentistry. 2012:34:e202-8.

Shipper G, et al. Marginal adaptation of mineral trioxide aggregate (MTA) compared with amalgam as a root-end filling material: a low-vacuum (LV) versus high-vacuum (HV) SEM study. Int Endod J 2004;37:325-36.

Silva GF, et al. Microparticulated and nanoparticulated zirconium oxide added to calcium silicate cement evaluation of physicochemical and biological properties. Journal of Biomedical materials research part A. 2014:102:4336-45.

Silva MJ, et al. Um modelo experimental in vivo para avaliar lesões de furca como resultado da perfuração. Int Endod J. 2009;42:922-9.

Silva LA, et al. Radiographic evaluation of pulpal and periapical response of dogs' teeth after pulpotomy and use of recombinant human bone morphogenetic protein-7 as a capping agent. J Dent Child (Chic). 2008;75(1):14-9.

Silva LA, et al. Direct pulp capping with a self-etching adhesive system: histopathologic evaluation in dogs' teeth.Oral Surg Oral Med Oral Pathol Oral Radiol Endod. 2009;108(1):34-40.

Silva LA, et al.. Histopathological evaluation of root canal filling materials for primary teeth. Braz Dent J. 2010 Jan;21(1):38-45.

Silva Neto, et al. Portland cement whit additives in the repair of furcation perforations in dogs. Acta Cirurgica Brasileira. 2012:27(11)809.

Silva Neto JD, et al. Root perforations treatment using mineral trioxide aggregate and Portland cements. Acta Cir Bras. 2010;25(6):479-84.

Silveira LR, et al. Bone repair process in calvarial defects using bioactive glass and calcium sulfate barrier. Acta Cir Bras. 2008;23:4-7.

Simonet W, et al. Osteoprotegerin: a novel secreted protein involved in the regulation of bone density. Cell. 1997;89: 309-319.

Simsek N, et al. Assessment of the biocompatibility of mineral trioxide aggregate, bioaggregate, and biodentine in the subcutaneous tissue of rats. Nigerian Journal of Clinical Practice. 2015;nov-dec. 18:6:739-43. 
Sinai I. Endodontic perforations: their prognosis and treatment. J Am Dent Assoc 1977;95:90-5.

Sinai $\mathrm{IH}$, et al. An evaluation of tricalcium phosphate as a treatment for endodontic perforations. J Endod, 1989:15:399-403.

Sluyk SR, Moon PC, Hartwell GR. Evaluation of setting properties and retention characteristics of MTA when used as furcation perforation repair material. J Endod. 1998;24:768-71.

Soares IMS. Resposta pulpar ao MTA - Agregado de Trióxido Mineral - comparada ao hidróxido de cálcio, em pulpotomias. Histológico em dentes de cães. Florianópolis, 1996. 74p. Concurso (Professor Titular) - Centro de Ciências da Saúde (Departamento de Estomatologia - Área de Endodontia), Universidade Federal de Santa Catarina.

Song JS, et al. Chemical analysis of powder and set forms of Portland cement, gray ProRoot MTA, White ProRoot MTA and gray MTA Angelus. Oral Surg Oral Med Oral Pathol Oral Radiol Endod 2006;102:809-15.

Takita T, et al. Effect of mineral trioxide aggregate on proliferation of cultured human dental pulp cells. Int Endod J 2006;39:415-22.

Tanomaru-Filho $\mathrm{M}$, et al. Evaluation of periapical repair following retrograde filling with different root-end filling materials in dog teeth with periapical lesions. Oral Surg Oral Med Oral Pathol Oral Radiol Endod. 2006 Jul;102(1):127-32.

Torabinejad M, Chivian N. Clinical applications of mineral trioxide aggregate. J. Endod. 1999;25:197-205.

Torabinejad $\mathrm{M}$, et al. Dye leakage of four root end filling materials: effect of blood contamination. J. Endod. 1994;20:159-63.

Torabinejad $\mathrm{M}$, et al. Physical and chemical properties of a new root-end filling material. J Endod 1995;21:349-53.

Torabinejad $\mathrm{M}$, et al. Antibacterial effects of some root end filling materials. J. Endod. 1995;21:403-6.

Torabinejad $M$, et al. Cytotoxicity of four root end filling materials. J. Endod. 1995;21:489-92.

Torabinejad $\mathrm{M}$, et al. Tissue reaction to implanted root-end filling materials in the tibia mandible of quinea pigs. J. Endod. 1998;24:468-71.

Torabinejad $\mathrm{M}$, et al. Bacterial leakage of mineral trioxide aggregate as a root end filling material. J. Endod. 1995;21:109-12.

Torabinejad $\mathrm{M}$, et al. Comparative investigation of marginal adaptation of mineral trioxide aggregate and other commonly used root end filling materials. J. Endod. 1995;21:295-9. 
Torabinejad $\mathrm{M}$, Kettering JD. Identification and relative concentration of $\mathrm{B}$ and $\mathrm{T}$ lymphocytes in human chronic periapical lesions. J Endod 1985;11(3):122-5.

Torabinejad M, Watson TF, Pitt Ford TR. Sealing ability of a mineral trioxide aggregate when used as a root end filling material. J Endod. 1993;19:591-5.

Tsesis I, Fuss Z. Diagnosis and treatment of accidental root perforations. Endod Top. 2006;13:95-107.

Unal GC, Maden M, Isidan T. Repair of furcal iatrogenic perforation with mineral trioxide aggregate: two years follow up of two cases. Eur J Dent 2010;4:475-81.

Vallés $\mathrm{M}$, et al. Influence of light and oxygen on the color stability of five calcium silicate-based materials. J Endod. 2013;39(4):525-8.

Vanni JR, et al. Radiographic evaluation of furcal perforations sealed with different materials in dog's teeth. J Appl Oral Sci. 2010 Aug;19(4):421-5.

von Stechow, K. Balto, P. Stashenko, R. Müller. Three-dimensional quantitation of periradicular bone destruction by microcomputed tomography. $J$ Endod. 2003;29:252.

Wada $\mathrm{N}$, et al. Periodontal ligament cells secrete the factor that inhibits osteoclastic differentiation and function: the factor is osteoprotegerin/osteoclastogenesis inhibitory factor. J Periodont Res 2001;36:56- 63.

Wang X, Sun $\mathrm{H}$, Chang J. Characterisation of $\mathrm{Ca} 3 \mathrm{SiO} 5 / \mathrm{CaCl} 2$ composite cement for dental application. Dent Mater 2008;24:74-82.

Wang $\mathrm{Y}$, et al. Effect of tricalcium silicate $(\mathrm{Ca}(3) \mathrm{SiO}(5))$ bioactive material on reducing enamel demineralization: an in vitro $\mathrm{pH}$-cycling study. Journal of Dentistry 2012;40:1119-26

Watts JD, et al. Effects of $\mathrm{pH}$ and mixing agents on the temporal setting of toothcoloured and gray mineral trioxide aggregate. J Endod. 2007;33:970-73.

Weine FS. Endodontic therapy. 6th ed. St. Louis: Mosby; 2004.

Wongkornchaowalit N, Lertchirakarn V. Setting time and flowability of accelerated Portland cement mixed with polycarboxylate superplasticizer. J Endod. 2011 Mar;37(3):387-9.

Xavier CB, et al. Root-end filling materials: apical microleakage and marginal adaptation. J Endod 2005;31:539-42.

Widbiller $\mathrm{M}$, et al. "Three dimensional culture of dental pulp stem cells in direct contact to tricalcium silicate cements". Clin Oral Investigations. 2016:20:2, 237-46.

Zairi A, et al. Periradicular tissue responses to biologically active molecules or MTA when applied in furcal perforation of a dog's teeth. Int J Dent 2012;257832. 
Zeferino EG, et al. Ex vivo assessment of genotoxicity and cytotoxicity in murine fibroblasts exposed to white MTA or white Portland cement with $15 \%$ bismuth oxide. Intern Endod J. 2010;43:843-848.

Zhao $\mathrm{W}$, et al. The self-setting properties and in vitro bioactivity of tricalcium silicate. Biomaterials. 2005;26:6113-21.

Zhou HM, et al. In Vitro cytotoxicity evaluation of a novel root repair material. J Endod. 2013;39(4):478-83.

Zhu YQ, et al. Adhesion of human osteoblasts on root-end filling materials. J. Endod. 2000;26:404-6. 

Anexos 



\section{ANEXOS}

$$
\text { ANEXO A - Certificado CEUA - FORP/USP }
$$

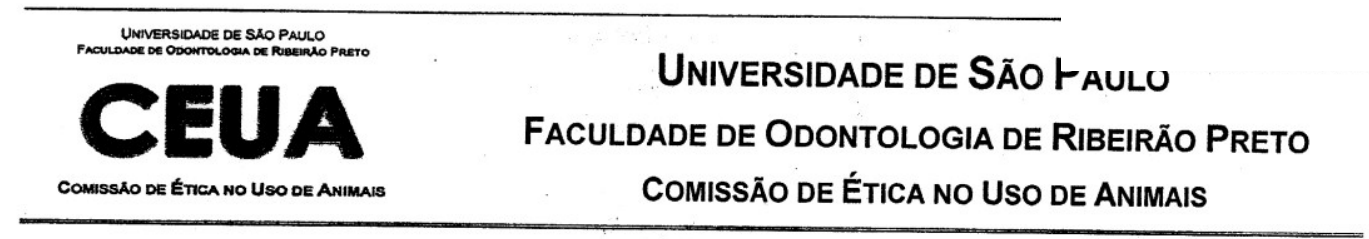

\section{Certificado CeUA - FORP/USP}

Certificamos que o Protocolo $n^{\circ}$ 2014.1.76.58.4 sobre a pesquisa intitulada "Resposta dos tecidos perirradiculares à biodentine ou MTA quando aplicados em perfuração de furca em dentes de cães", sob a responsabilidade da Profa. Dra. Alexandra Mussolino de Queiroz, está de acordo com os Princípios Éticos na Experimentação Animal adotados pela Comissão de Ética no Uso de Animais da Faculdade de Odontologia de Ribeirão Preto, USP, foi APROVADO em reunião da CEUA de 15/07/2014 (totalizando 03 animais).

We hereby certify that the protocol $n^{\circ} 2014.1 .76 .58 .4$ regarding the research entitled "Periradicular tissue response to biodentine or MTA when applied in dog's teeth furcation perforation", under the responsibility of Profa. Dra. Alexandra Mussolino de Queiroz, is in accordance with the Ethical principles in animal research adopted by the Animal Research Ethics Committee of the School of Dentistry of Ribeirão Preto, University of São Paulo, Brazil, and was approved in 15/07/2014 (totalizing 03 animals).

Ribeirão Preto, 15 de julho de 2014.

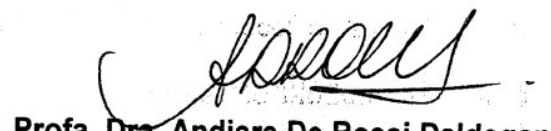

Profa. Dra. Andiara De Rossi Daldegan

Coordenadora da CEUA - FORP/USP 
ANEXO B - Manual de Instruções do Fabricante - PROROOT®MTA

DIRECTIOES FOR USE

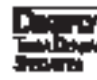

PRoRoOT ${ }^{8}$ MTA

(MinERAL TRIOXIDE

AgGREGaTe)

RoOT CANAL

REPAIR MaTerial

DEMTSPLY Tutsa Denta I Spectalles

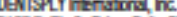

S100 Esely Dhive, site 30

Thas $0 \times 76135$

1- $100-602-1212$

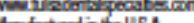

Utrutactes in tre US.

Authered Aepresentativ

Denisprideing Gint

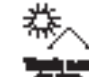

Ce

D-734t Kanctare

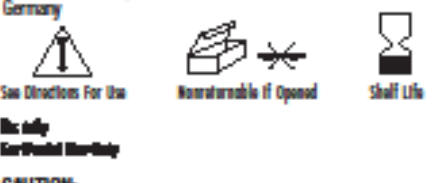

CANTON:

Profoot MTA root repalr matarta is a powder conskling of tne hydrochllic particles that set in the presenoa of ugler. b form a strong imoermeatla barris that fuly cures over a ur-Wear perion.

mDicanons:

Profloot MTA root repalr mataral is indkaled for use as:

- A root end filing matara

- For tha repar of root canak as an ackal plug

- For repali of root perbaratons duting root

- As a consequence of intema resorption

- As a pulp cacping materal

CONTRANDICATIOMS:

Mone known.

PRECAUTIONS:

- Propoot MTA root repal matertal pouches must be kept

- Propoot MTA root repar matertal must be stored in a dry

area to avold dagradation by moisture

- Profoot MTa root repair matertal must be kegt in its

saded paokaging probr to use to avild degracition

- Propoot MTA root repali malertal must be plapas

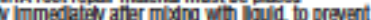
detydracion diring seiting.

- Exoess waler will retard a aring proogss. Booss moktire in

- Do not imigate after placing ProRoct MTA root repalr materta.

Demove exoss ulater utth mokst cotion palat.

DIRECTIONS FOR USE:

REPAR OF PERFOAMTONS SECOMDARY TO

1. Using a rutber dam, debride the root cand systam using ntrana instuments and Irigate whin Naocl. For canal system for one week.

Pboa a tamporary resturation to seal the

3. Afar one week using a nutber dam, remove the and isstrument as needed.

Dry the canaks with paper ponts and idently the reorotive defect ste.

5. Coturde al the canal spase axical in the defect.

PREPARE THE PROROOT MTA ROOT

REPAR WATEUL ACCORDING TO THE
DRECTICWS FOR USE

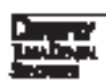

7. Using the carrer, dspense the matertal into the rescroblve defiat ste. Condanse the Profoot MTA root repar matera in he canty using a smal

8. Confrm the plapement of ProPoot MTA roct regal malerial whin a radilogach. If an adequate barm

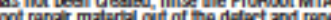
tha procadure.

9. Take a wet cothn pelit, vemove exress moleture from the pellat and place in fhe cana. Seal tha access
prepardition with a temporary restoraton for a minimum of bur hours.

10. After four hours, or at another appointmant, use revalr matertal Th's materia should be hard. If not, inse and repast the applination.

11. When the ProPoct MTA root reoal matartal is hardenad, ofturate the remaining canal spapa. a a permanant part of the root canal filling.

INTEANAL REPAR OF UTROGENIC PEPFORATIONS:

1. Uuing a rutber dam, debrite the root canal system,

2 Dy the cand system with paper points and lsolde

coturate al the cand space, apical to the perbration.

4. PREPARE THE PAOROOT MTA ROOT REPAIR INSTRUCTIONS PROVIDED.

5. Using the carrier, dspanse the matertal into the perfordibn ste Conderse fhe Propoot MTA rod pumer, cotion pallats or paper pohts

6. Contrm placement of the ProAoot MTA root repair maderial whin a raslograph. If an adequate barler has not baen crated, rinse the Propoot MTA root repdir

7. Take a wet coton pelet, remove exress mosture from tha dellet and plase in the cana. Seal the acoss orepardion with a temperary restordion for a minimum

8. After four hours, or at another appointmant, use a nitoer dam and examine tha Profloot MTA root repar materral. This cerment s,

9. When the ProRoct MTA root regar matara is hardenot, chisuale the remaining canal spape. The permanant part of the root canal niling

ROOT APEOACATON:

1. Using a nutber dam, debride the root canal system

2 Dry the cand system with paper points and for

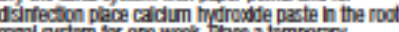
canal system tor one week prace a temporar restraction to saal the access opering.

3. After ona wesk, using a rubber dam, remove the caOH from the canal systam using NaOCI rrigralon papa points.

4. PREPARE THE PROROOT MTA ROOT REPAN MATERML ACCOADING TO THE

5. Uaing the carler, aspense the cerment int the apica reglon Condense the Propoot MTA root win plipoess or paper points. Creda a trreat to repalr malertal

6. Conftrm plaxement of tha ProAcot MTA root repar malertal whin a raslogran. if an adequade barrer has

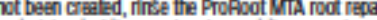
malerial out of the canal and repaat the procedure.

7. Take a wet cothn peliet, remove excess molsture from ha pellet and place in fie rand. Seed the acoess preparation with a emporary restoration for a minimum

8. Alter four hours, or at a lats apcointment, use a nitoer dam and examine tha Profoot MTA poot not, inse and repost the apdiration.

9 When the ProPodt MTA root regar matarta hardenat, obturade the remaining caral spasa. a permanant part of the root canal niling

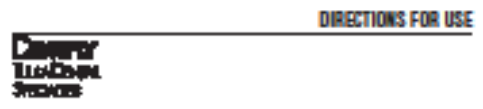

ROOTEMD FUU:

1. Galn acosss b tha rootend and resect the root wh a surgikal ber.

2 Whth an uttrasonic th, prepere a chass I rootsid canty wrepar

3. bolate the area. Dry the rodtend carty with paper points Actileve hemostrok whin wa

4. PAEPARE THE PROROOT MTA ROOT, UXXVIC NSTRUCTOKS PROVIDCD.

5. Using the carrier dspense the matertal into

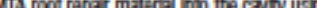
a simal pumper.

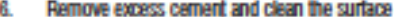

of the root with a most pleces of galins or Telas.

7. Contim placement of the Propoot MTA root repair recair matertal remians as a permanant part of the root cand filing.

PULP CAPPINE:

1. Under a rubber dam, complate a cavty preparation outine ushng Wigh-speed burs, unds constant water coollng.

2 I carles are present, ecarde using a rund bur $\mathrm{n}$ a

3. Pinse the carty and exposure slle(5) with $26 \%$ - $5 \%$ coltin palat moiktened with $\mathrm{NaOC}$.

PREPARE PROROOT MTA ACCORDING TO

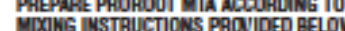
Using a smal bal apolrabr, or simllar device, apch Remove the exoss mokture at the stia with a dry

7. Aoply a smal amount of Dyract Row foucble

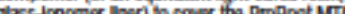
giass-anomer iner) bo cover tha Profoot MTA

8. Alch he remaining cavty walk with $30 \%-37 \%$ thoshoric asid get br 15 seconds. Anse tror

9. Dry the cavity gently, leeving the dentin mokst, bit not wet. Apoy P.me s Bond Nit malertial, or an instructions

10. Pace TPH Spectrum composthe materal or an equivalsnt according to is instructors.

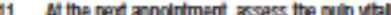

At the nest acoditiment assess the pulp vta radiograchinaly every three ob sta months or

PROROOT MTA ROOT REPAIR MATERIAL

MXING NSTRUCTIONS:

Moter Propoot MTA root reepar material does not set 3

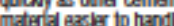

- Open a pouch of Profooot MTA root resair malerial and disparsa the powdar ontb a mbeng pad.

- Pull off the end of a Profoct I Iuid micro-dosa ampoule and suleeze out cornants orto the mbeny pad naxt io the root repalr materia.

- Gradialy hoorporate ne lquid hto the cxment

using the ProAoot MTA mbeng stox

Mxx the materta with the losus for about one minus:

to ensure al the powder paridas are hydrated.

- If needed (one exta ampoula is provided, sterla wates added b makp the matartal Into a thick cramry

1. Adding too much, or too Ittile lquid wil reduce the utimate strength of the materta. 2 The ProAost MTA root reqair material will set over atout five mirutes. If more working tume is gause par is prevent evaporaton. 
ANEXO C - Manual de Instruções do Fabricante - BIODENTINE TM
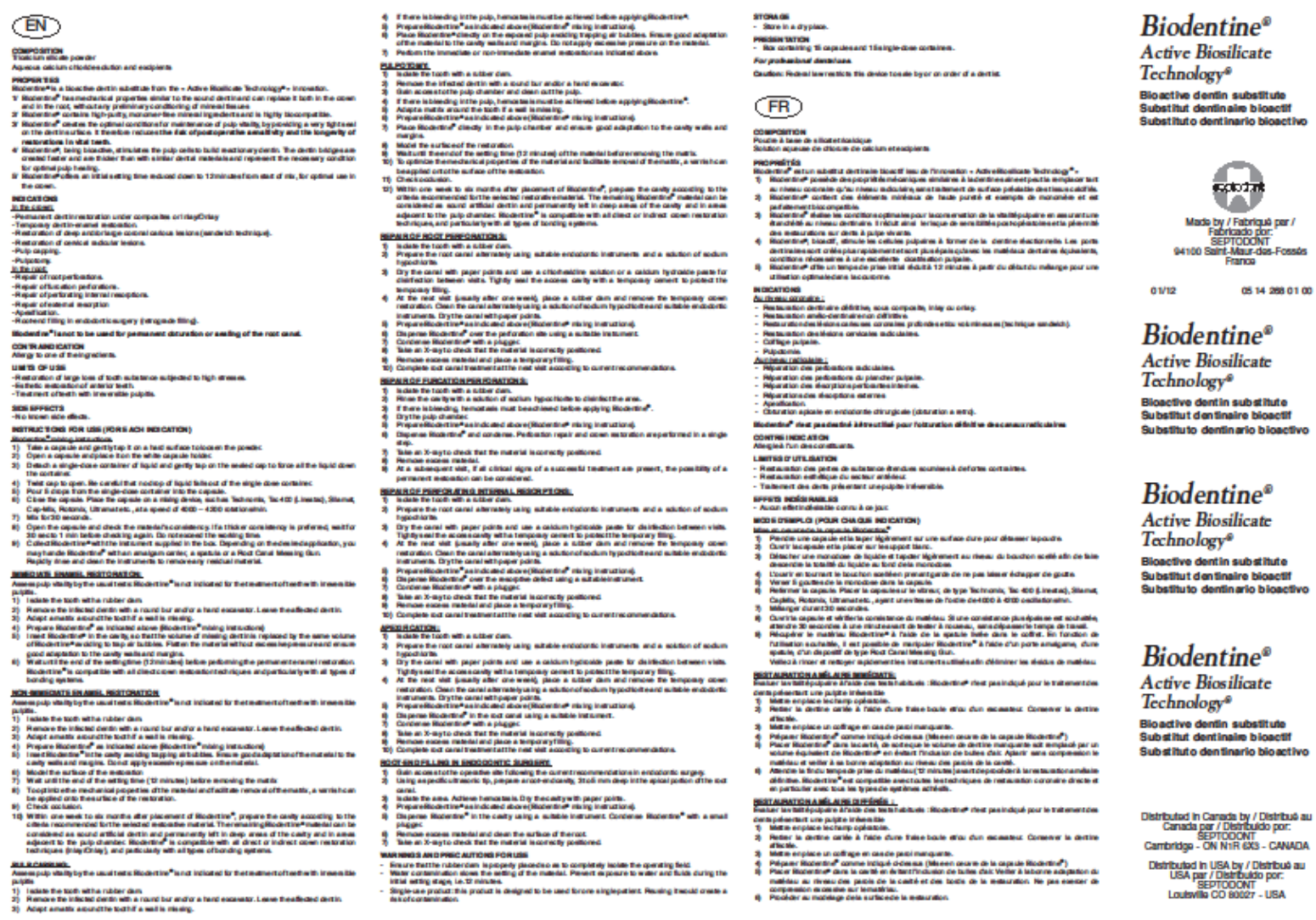

Biodentine Active Biosilicate
Technology

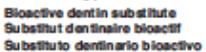

Biodentine Active Biosilicate

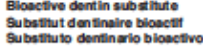

Biodentine Active Biosilicate Technology"

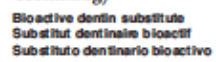

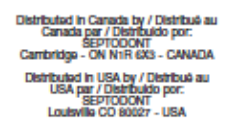

